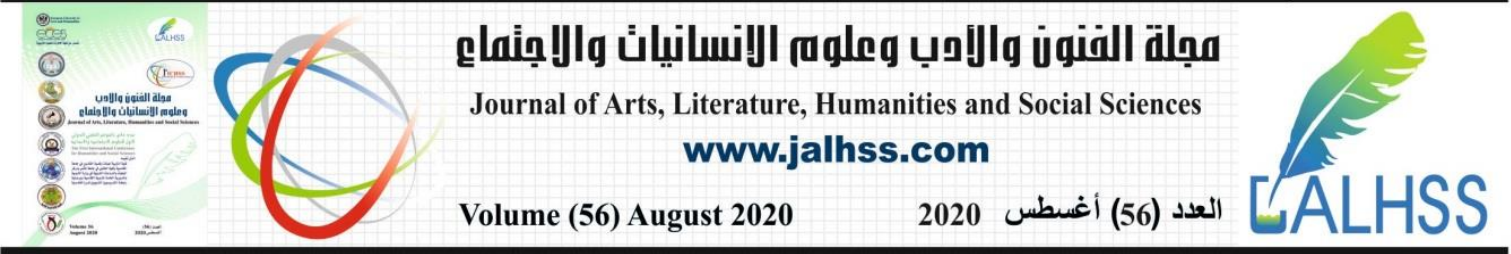

\title{
أخبار بني أمية في مرويات المدائني (ت: 225 هـ)
}

\author{
أ.م. نجلاء كريم مهدي \\ قسم السياحة الاينية ـ كلتية العلوم السياحية ـ جامعة كربلاء ـ ـ العراق \\ najlaa.k@uokerbala.edu.iq الايميل
}

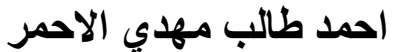 \\ قسم ادارة المؤسسات الفتدقية ـ كلية العلوم السياحية ـ جامعة كربلاء ــ العراق \\ ahmed.t@uokerbala.edu.iq الايميل
}

يعد علي بن محمد المدائني من ابرز علماء القرن الثالث الهجري ، قضى شطر ا كبير ا من حباته بنقل الروايات

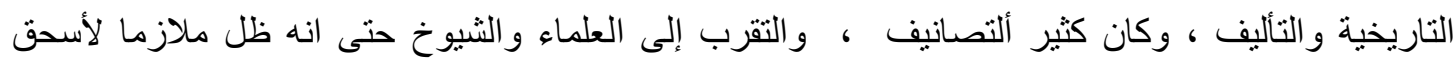
الموصلي ، كما اهتم بنقل الثعر فقد نقل أشعار الفرزدق ، تنوعت رواياته إذ نقل العديد من روايات سيرة الرسول و آل بيته (عليهم السلام ) كما انه نقل أخبار الخلفاء الر اشدين ، و الأمويين ، ونقل العديد من أخبار العباسيين ، وصب اهتمامه في نقل روايات فتوح الدولة العربية الاسلاميه في المشرق حتى انه ألف كتابا في الفتوح ، و وان دل ذلك على شي فانه يدل على عمق اطلاعه وتمكنه من نقل الروايات التاريخية بدقة ملفتة للاهتمام ـ وقد بلغت مؤلفاته حو الي مائتي مصنف ، فالمدائني ظهر عنده الأتجاه نحو جمع اوسع وتنظيم اوفى للروايات التاريخية

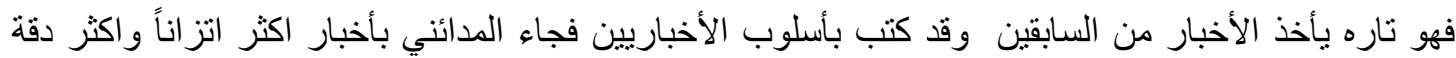
ممن سبقوه عن الحوادث و المواضيع التي تحدث عنها حنى قال في حقه النحوي ، من ار اد اخبار الجاهلية فعليه بكتب ابي عبيدة ، ومن اراد اخبار الأسلام فعليه بكتب الدائني ، وقد مدحه علماء الرجال وقالوا عنه عجباً في

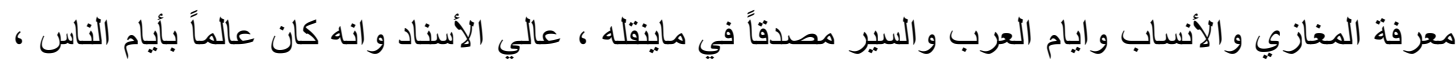

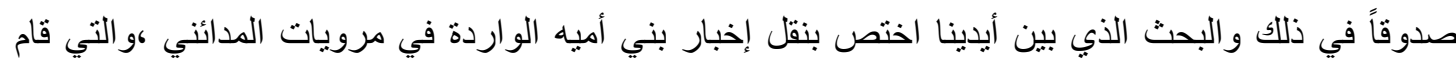
الباحث بجمعها ، و البحث عنها في مصادر التاريخ ، وكتب الفقه و الحديث ، وكتب الرجال . 


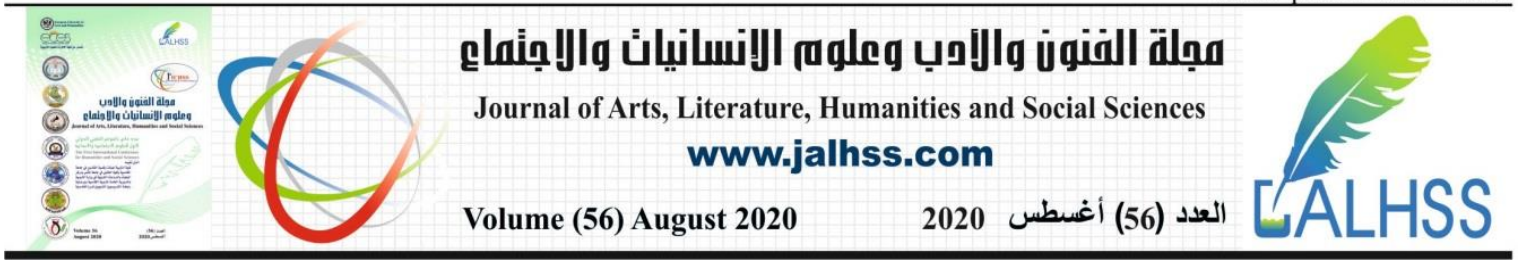

\title{
The News Bani Aumayah in the Narrations of Al-Madaini (D: 225 AH)
}

\author{
Assist. Lect. Naglaa Karim Mahdi \\ Department of Religious Tourism - College of Tourist Sciences \\ Karbala University - Iraq \\ Email: najlaa.k@uokerbala.edu.iq \\ Assist. Lect. Ahmed Talib Mahdi Al-Ahmar \\ Department of Management of Hotel Establishments - College of Tourism Sciences \\ University of Karbala - Iraq \\ Email: ahmed.t@uokerbala.edu.iq
}

\begin{abstract}
Ali bin Muhammad Al-Madaini is considered one of the most prominent scholars of the third century AH. He spent a large part of his life transmitting historical narrations and authorship, and he was a lot of typologies, and he approached the scholars and sheikhs until he remained attached to Isaac Al-Mawsali. Many of the narrations of the biography of the Prophet and his family (peace be upon them), as he transmitted the news of the adult caliphs and the Umayyads, and conveyed many news of the Abbasids, and poured his interest in reporting the accounts of the conquest of the Islamic Arab state in the East until he wrote a book in Al-Futuh, and if that indicates something, it is It indicates the depth of his knowledge and ability to purify Historical novels accurately striking interesting. In this study, health nutritional techniques, methods and programs used in health centers, resorts and hospital hospitals, the extent of the staff's commitment to these programs, the reflection of food programs on the inmates, the discussion of previous research on foreign specialization and their relevance to the present and modern technology used for services, hospital and food care. His books amounted to about two hundred works, and the research in our hands is concerned with the transmission of the news of his illiterate sons in the narrations of the cities, which the researcher collected, and searched for in sources of history, books of jurisprudence and hadith, and books of men.
\end{abstract}

Keywords: Bani Aumayah, Al-Madaini. 


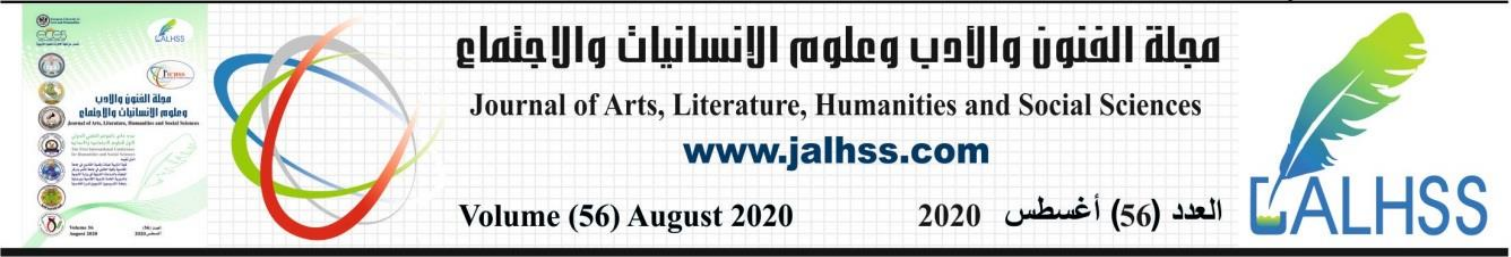

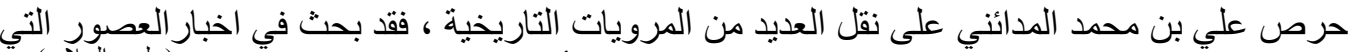

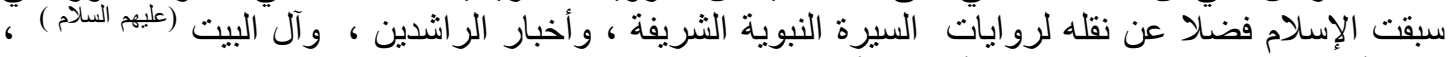

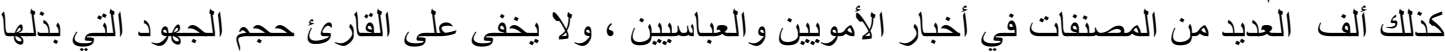

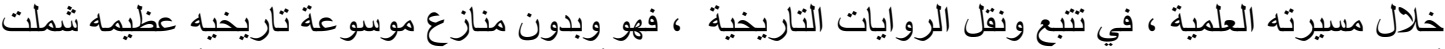

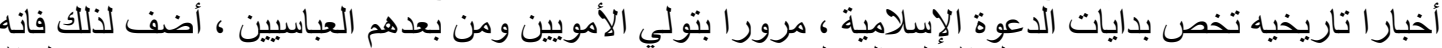

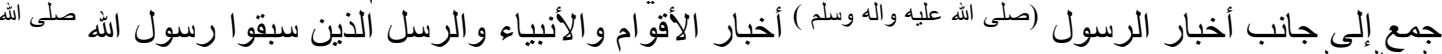

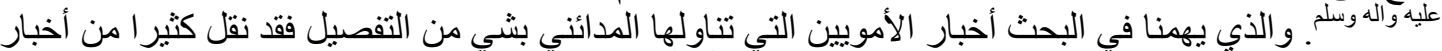

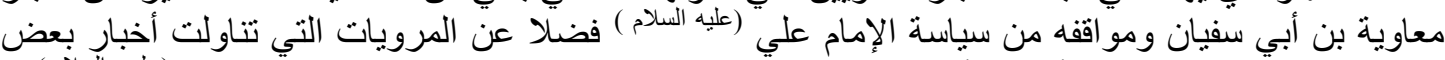

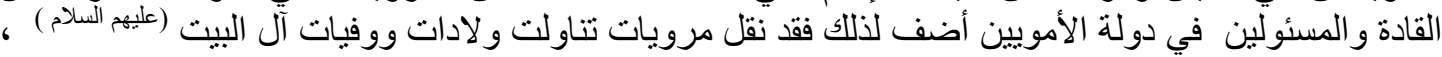

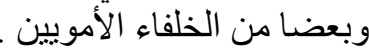

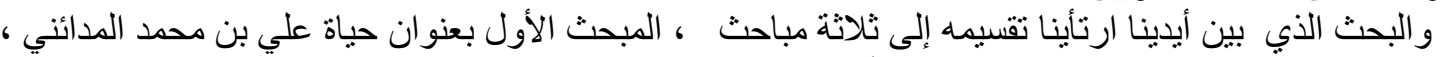

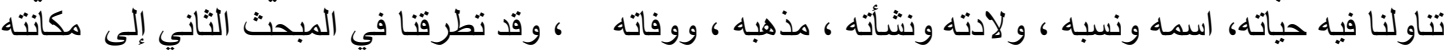

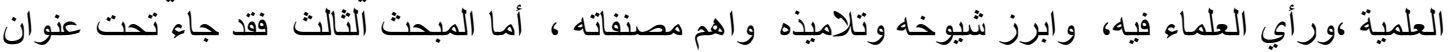
أخبار بني أميه في مرويات المدائني ،وقد اعتمدنا في البحث على عدد من المصادر والماهي المر اجع الحديثة نذكر منها على سبيل المثال لا الحصر كتب التر اجم ومنها كتاب الثقات لابن التاب حبان (ت: 354 هـ ) ، كتاب تاريخ مدينة

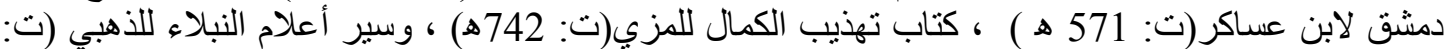

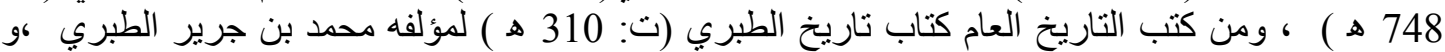

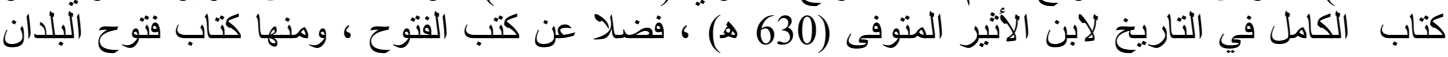
للبلاذري ، (ت: 279 هـ ).

\section{المبحث الأول: حياة المدائني (ت: 225 هـ )}

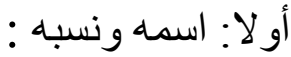
المدائني : علي بن محمد بن عبد الله بن أبي سيف ، أبو الحسن المدائني ، مولى عبد الرحمن بن سمرة القرشي .

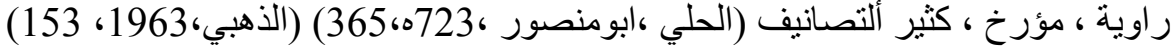

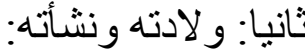
ولد علي بن محمد المدائني في البصرة سنة (135 هـ)، سكن المدائن، ثم انتقل إلى بغداد و أطال المقام بها إلى أن

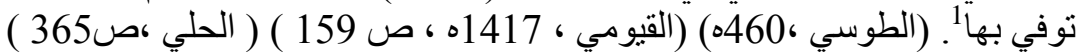

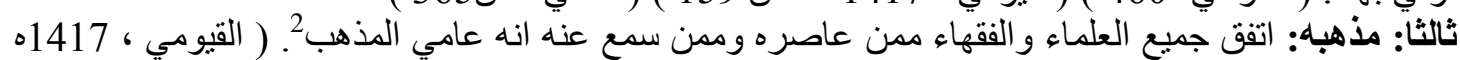

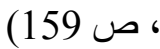

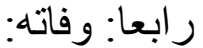

توفي علي بن محمد المدائني في بغداد سنة (225 هـ ) ، وذكرت بعض النه المصادر انه نوفي بمكة3 (الذهبي ،

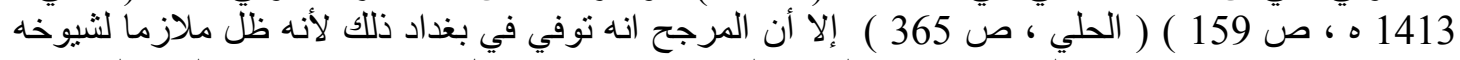

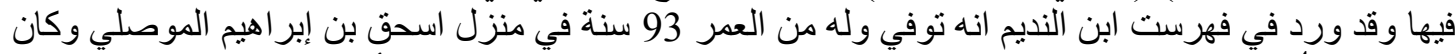

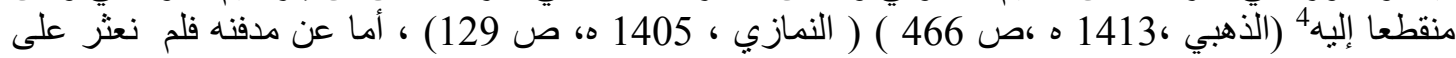

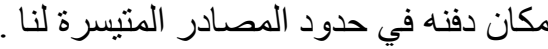

\section{المبحث الثاني: مكانته العلمية}

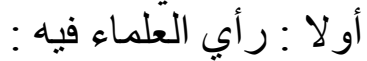

نال" علي بن محمد المدائني مدح العلماء والفقهاء فقد مدحه الطوسي بقوله :" المدائني عامي المذهب ، كله

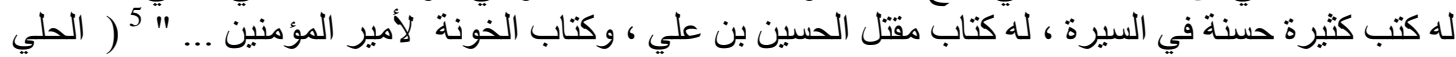




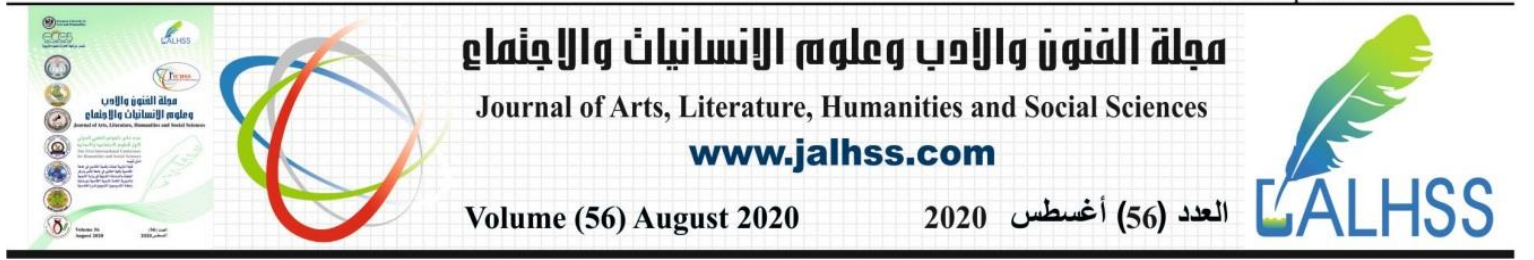

،ص 365 )( بحر العلوم ، 1972 ، ص 262 ) (وقد أنثى عليه ابن تغري بردي بقوله : " تاريخه أحسن

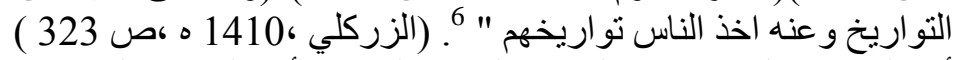

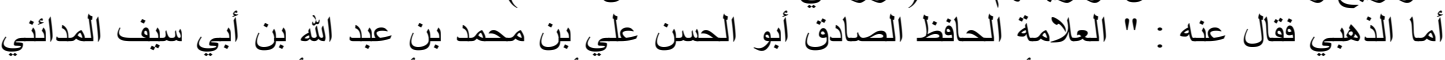

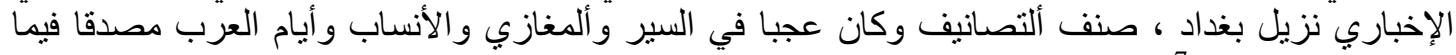

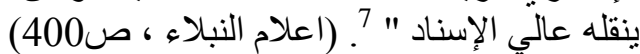
وقد مدحهة تُعلب النحوي بقولة : " من أر اد أخبار الجاهلية فعليه بكتب أبي عبيده ، ومن أر أراد أخبار الإسلام فعليه

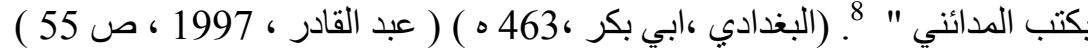

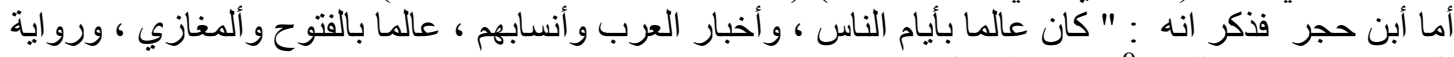

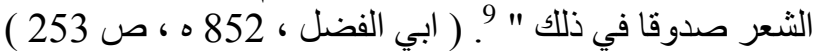
وقد ورد مدحه في الوافي بالوفيات للصفدي بقوله : " أبو مخنف بأمر العراق وفال وفتوحها وأخبارها ، و المدائني

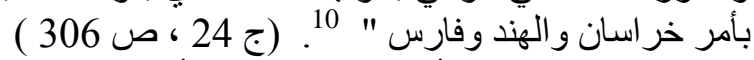

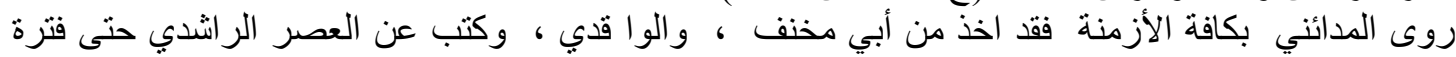

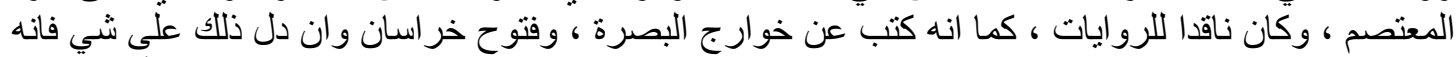

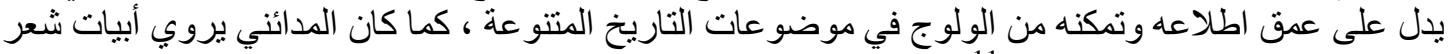

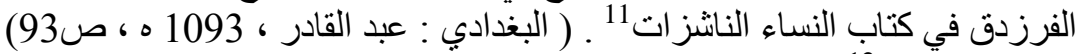

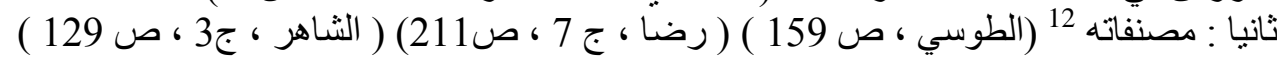
كما ذكرنا سابقا أن المدائني امتاز بتنوع ثقافته وقدرته على البحث و والتأليف ، لذانلك بلغت مؤلفاته نيف ومائتي

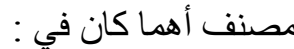

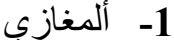

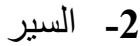

$$
\begin{aligned}
& \text { 3- - أخبار النساء } \\
& \text { 4- - تاريخ الخلفاء } \\
& \text { 5- - تاريخ الوقائع و الفتوح }
\end{aligned}
$$

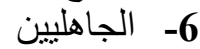

$$
\begin{aligned}
& \text { 7- } \\
& \text { 8 - - - - - البلدان } \\
& \text { 10- أمهات النبي صلى الشه عليه واله وسلم }
\end{aligned}
$$

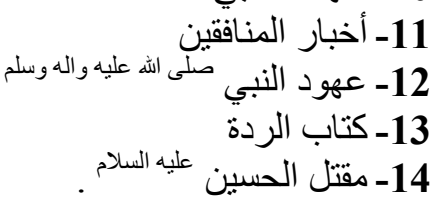

9- - 9- بقي من كتبه المردفات من قريش رسالة طبعت بمصر 1951 م م.

ثالثا : شيوخه13 : ( المزي : ابي الحجاج ، ت 742) (معروف ، 1406 ه ، ص 129) (الذهبي ،

تجنبا للإطالة و الإسهاب فقد أرتاينا أن نورد أسماء ابرز شيوخه الذابد الذين تتلمذ عليهر :

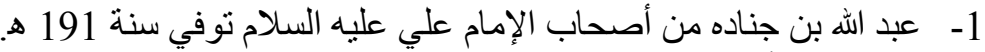

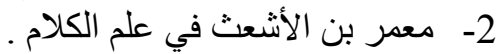

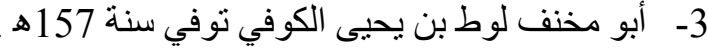

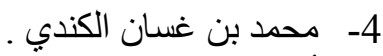

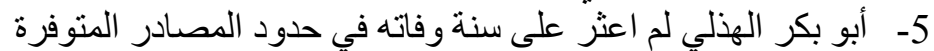

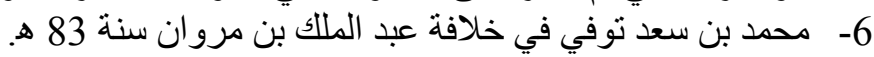

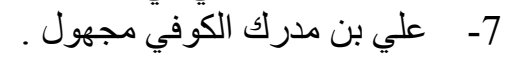




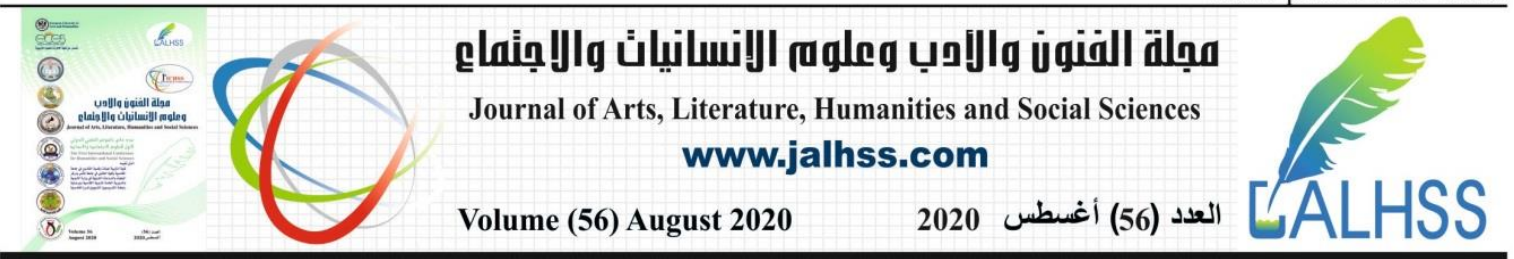

8- عو انة بن الحكم الكوفي أكثر الرواية عنه المدائني توفي سنة 158.

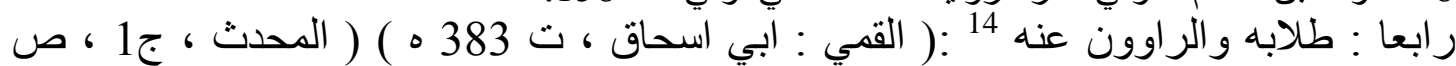

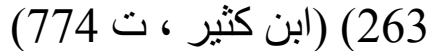

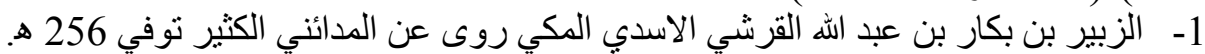

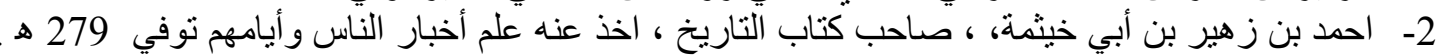
3- القمي صاحب كتاب الغارات ، روى عنه خطب الإمام علي توفي سنة 329هـ .

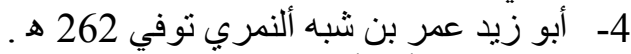

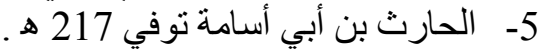
6- محمد بن صالح المدني الأزرق توفي سنة 252.

المبحث الثالث : أخبار بني أميه في مرويات المدائني

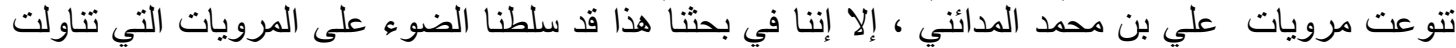

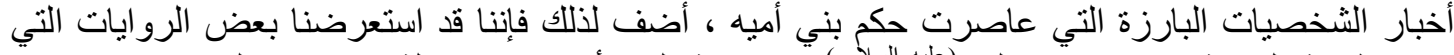

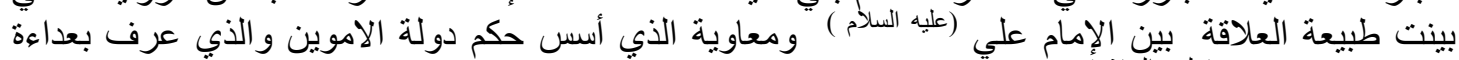
وبغضه لآل البيت (عليهم السلام ) وقبل الولوج في تللك المرويات توجب على الباحث أن يتطرق لبعض الأحداث التي بينت جذور العداء التاريخي

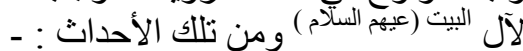

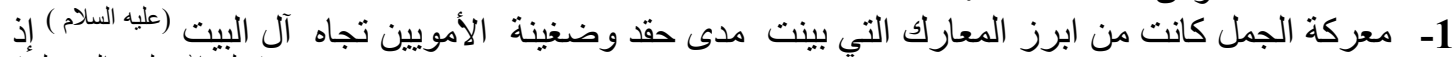

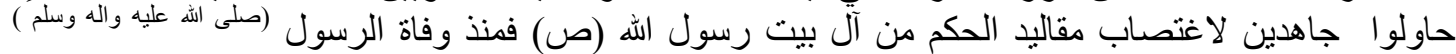

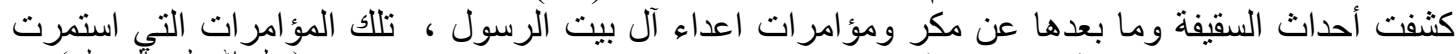

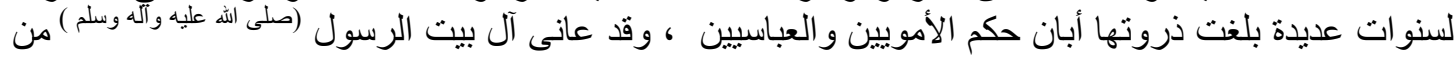

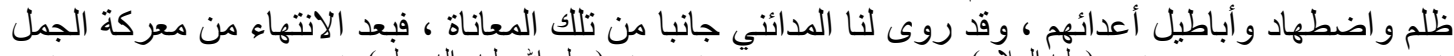

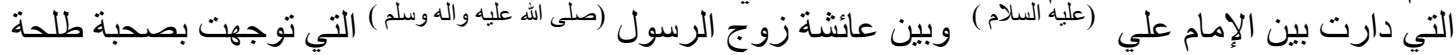

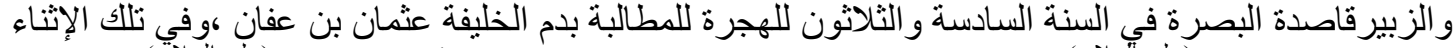

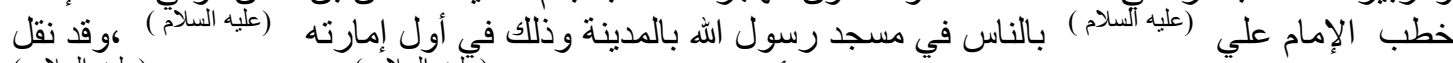

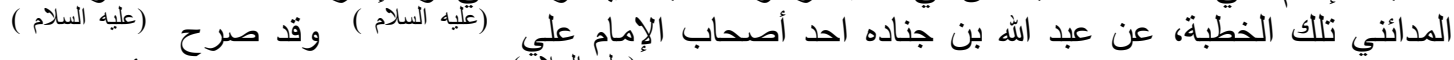

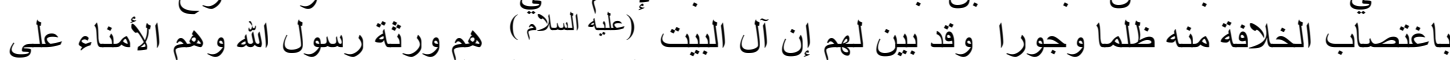

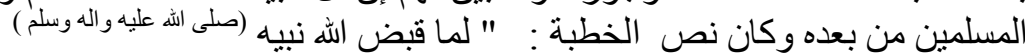

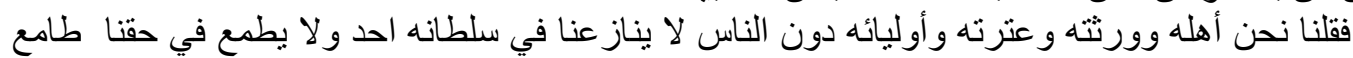

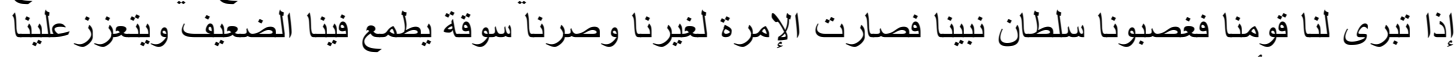

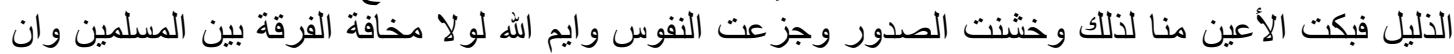

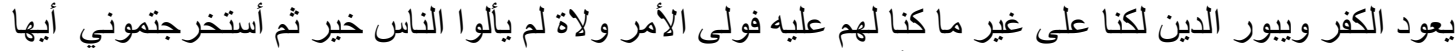

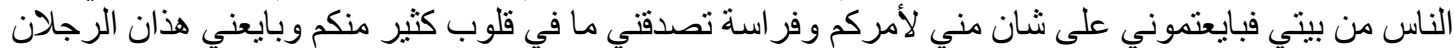

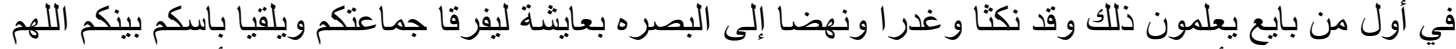

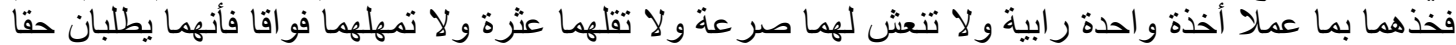

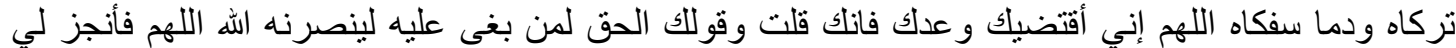

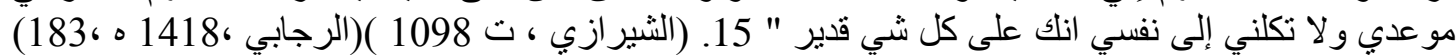

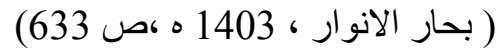

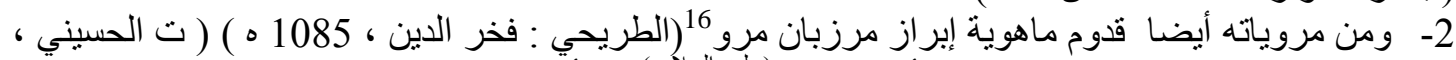

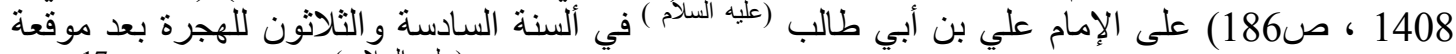

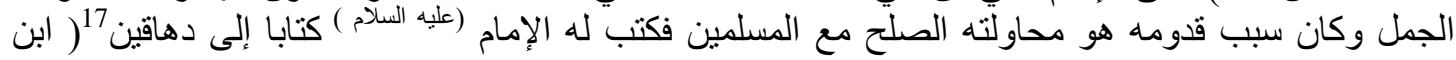
منظور : جمال الدين ، ت 711 ه ) (لسان العرب ، 1405 ه ،ص الع 107 ) مرو و الجند ومن كان معهم في " مرو الإن 


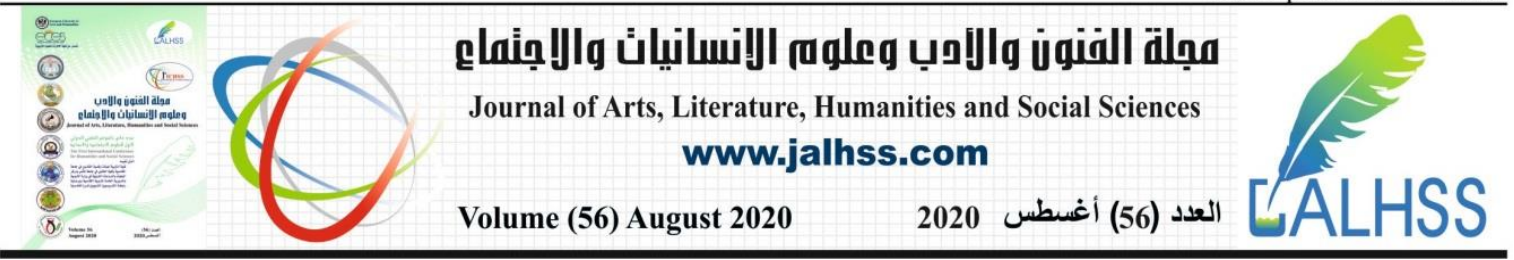

بسم الله الرحمن الرحيم سلام على من اتبع الهدى أما بعد فان ماهوية إبراز مرزبان مرو جاءني إنى واني واني رضيت

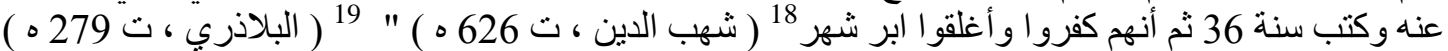

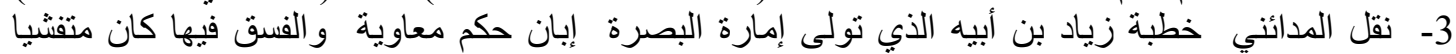

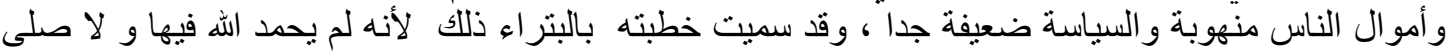

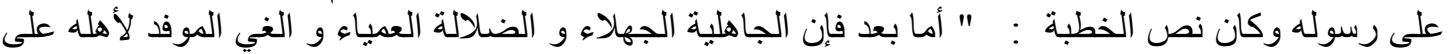

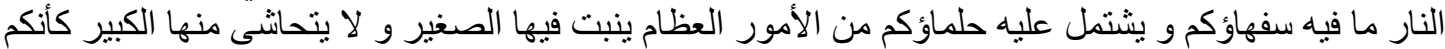

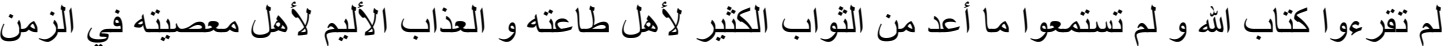

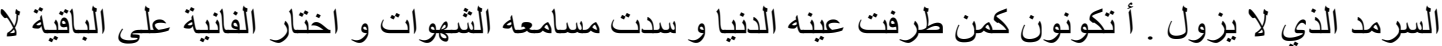

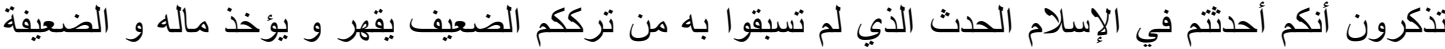

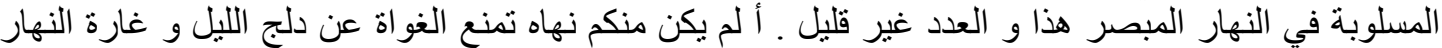

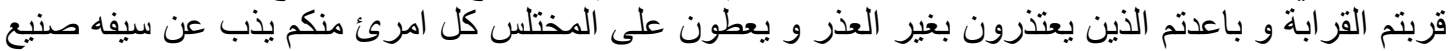

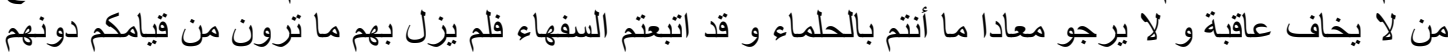

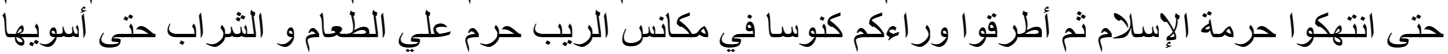

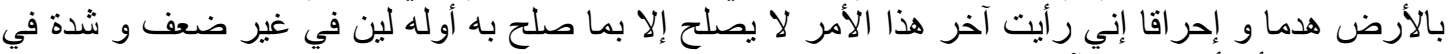

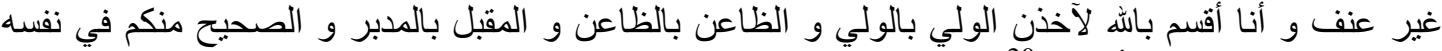

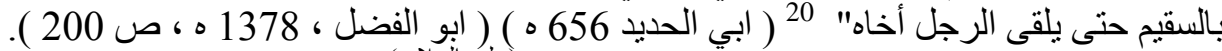

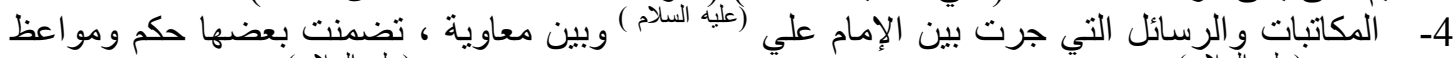

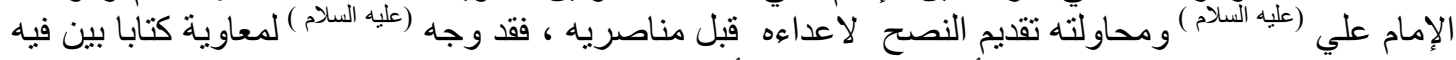

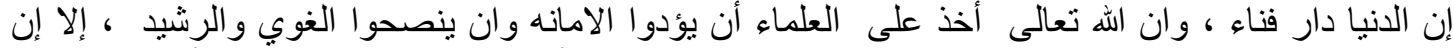

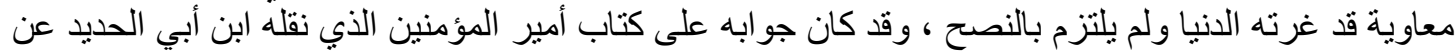

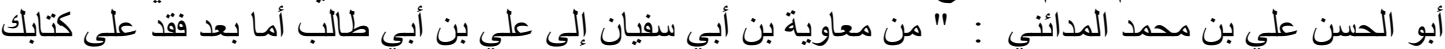

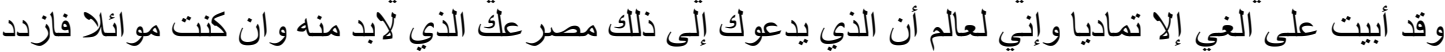

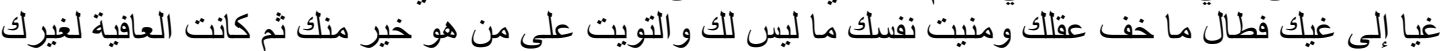

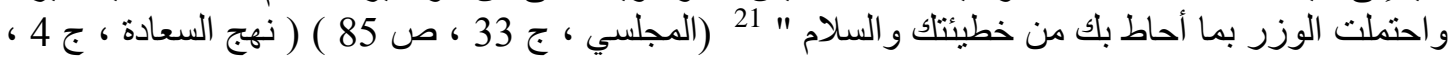

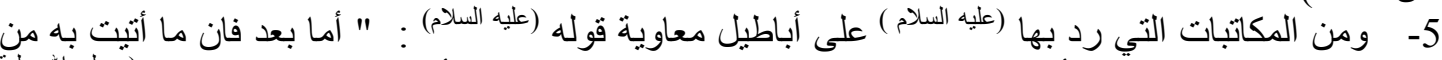

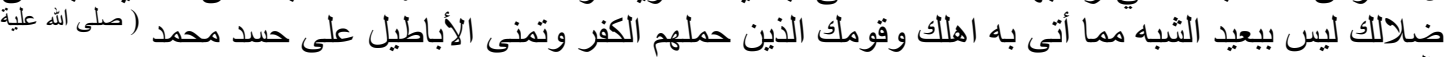

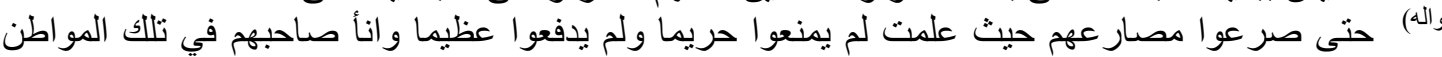

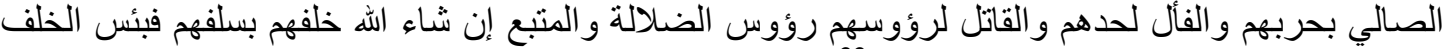

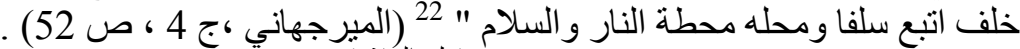

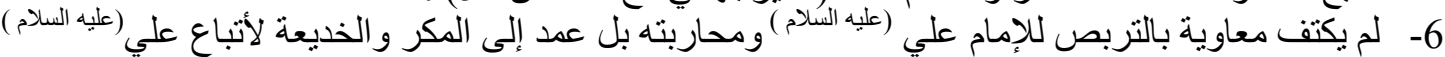

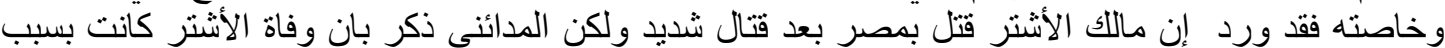

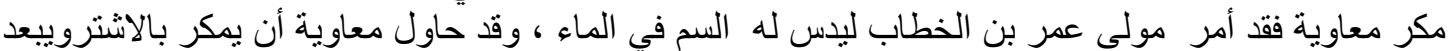

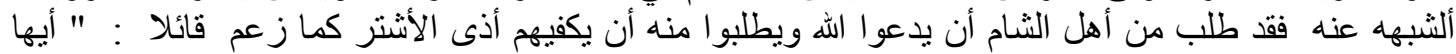

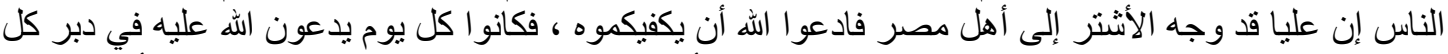

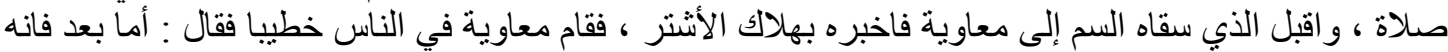

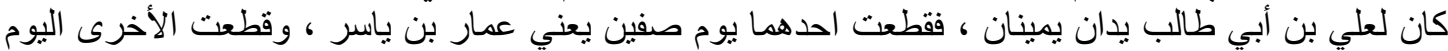

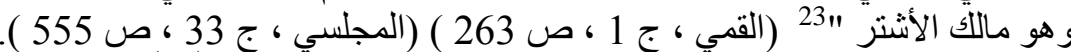

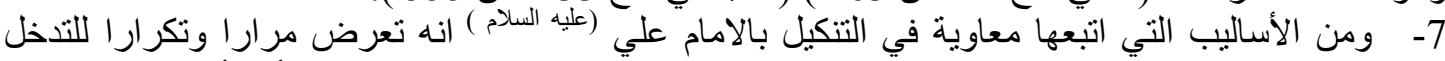

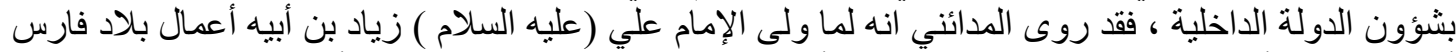

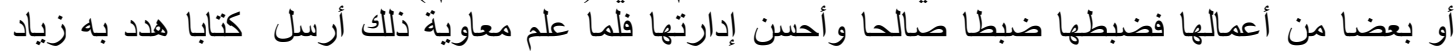

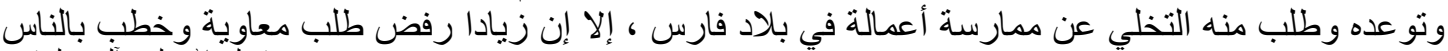

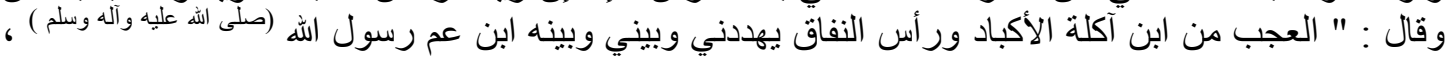




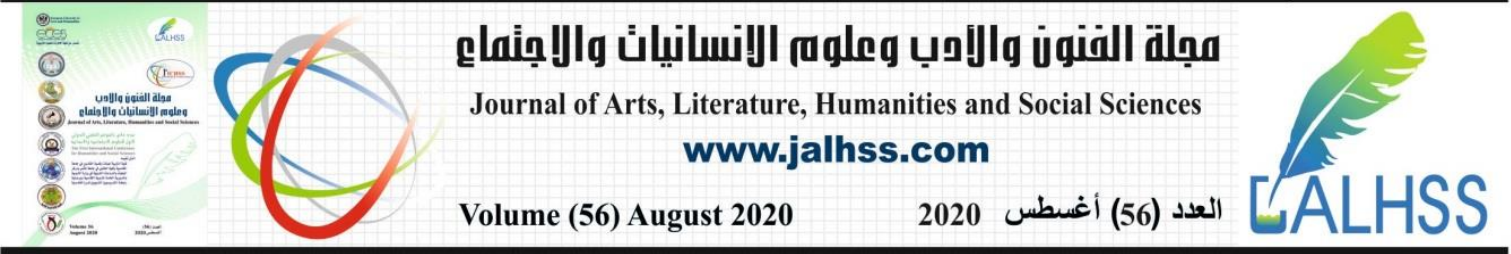

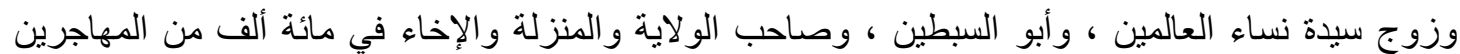

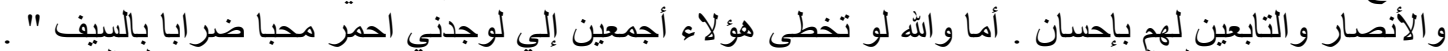

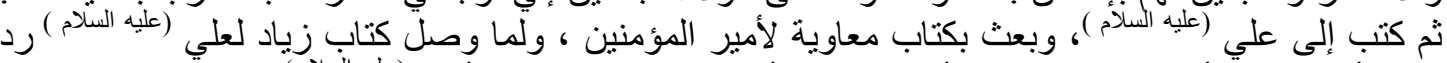

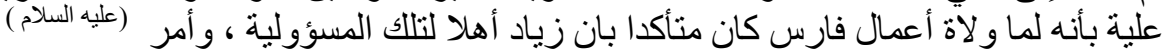

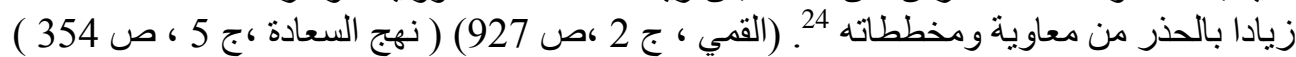

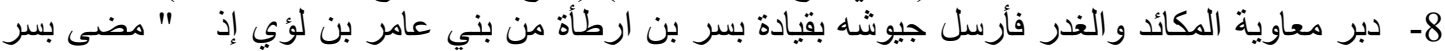

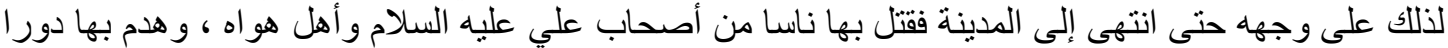

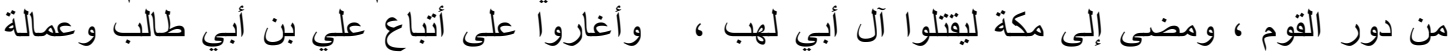

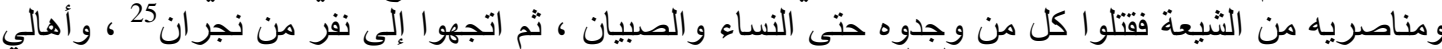

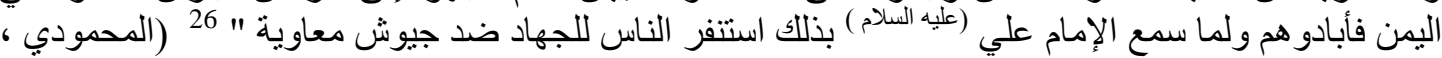

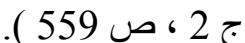

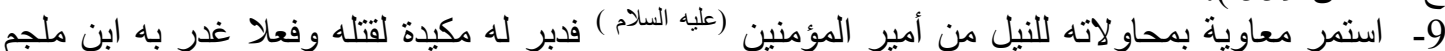

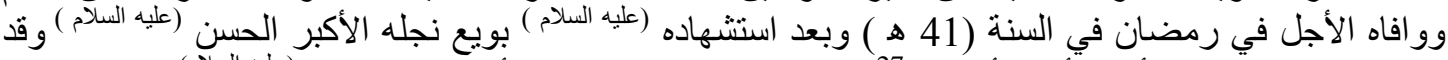

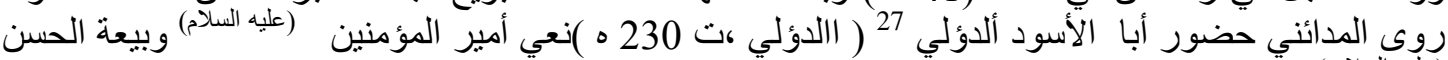

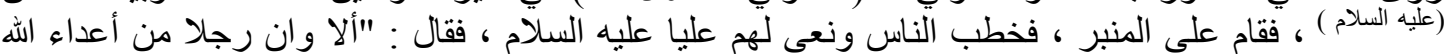

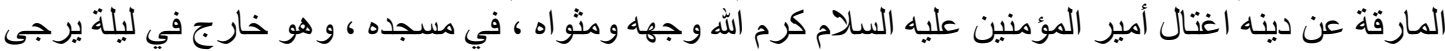

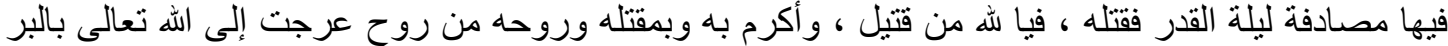

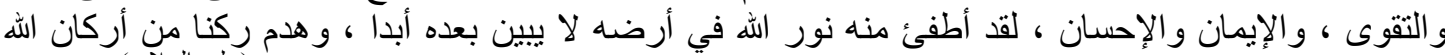

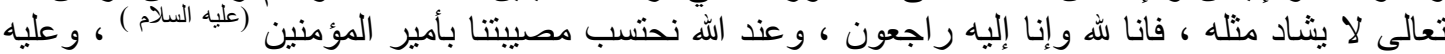

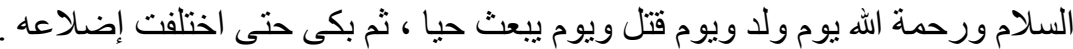

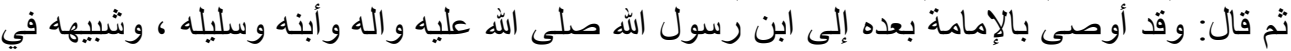

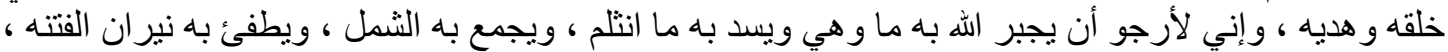

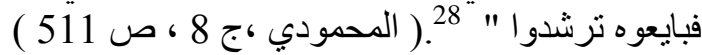

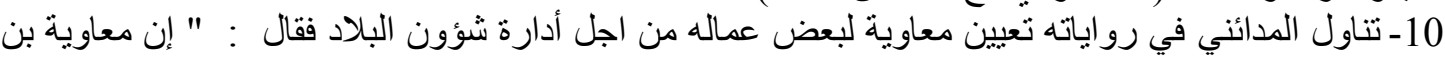

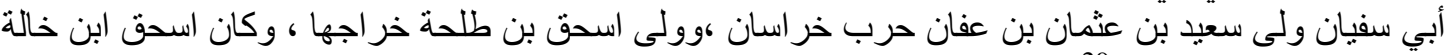

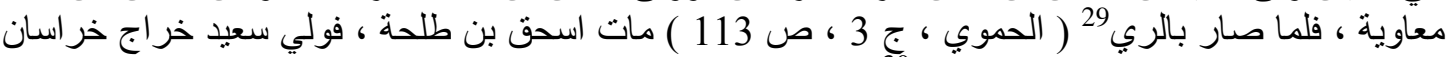

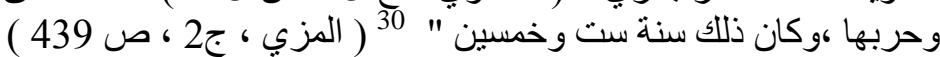

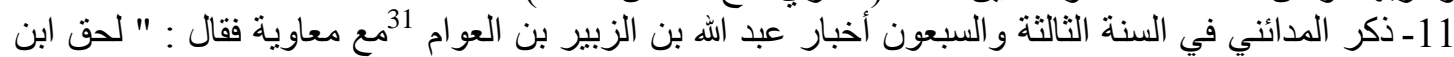

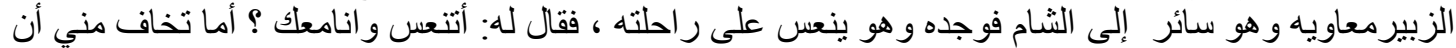

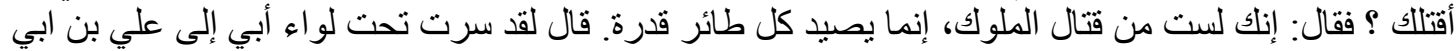

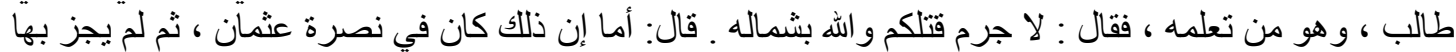

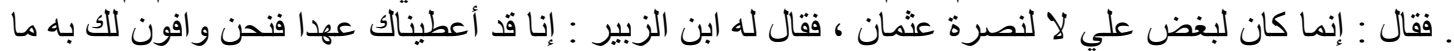

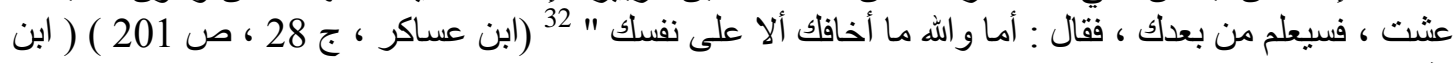

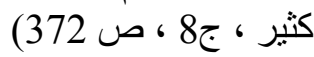

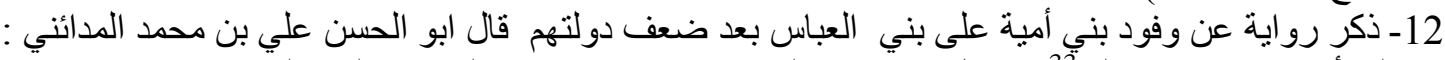

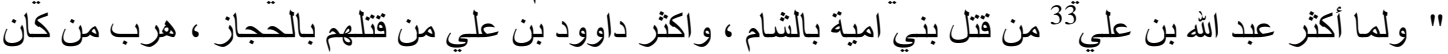

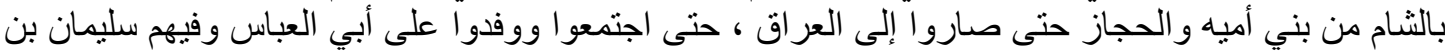

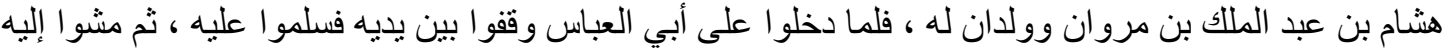

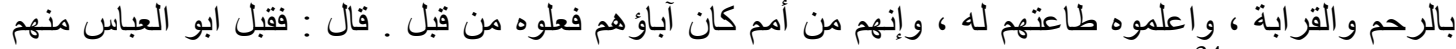
وقربهم و ادناهم " 34 (الكوفي ،ت

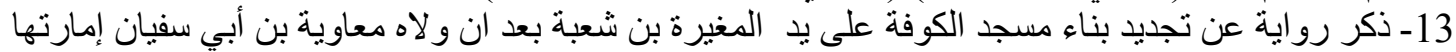

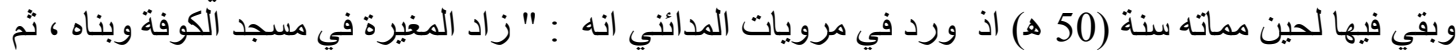

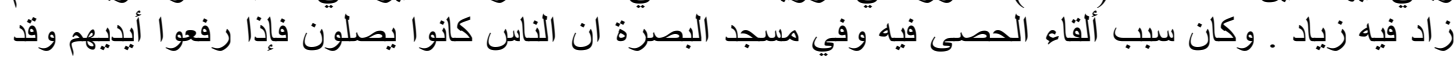




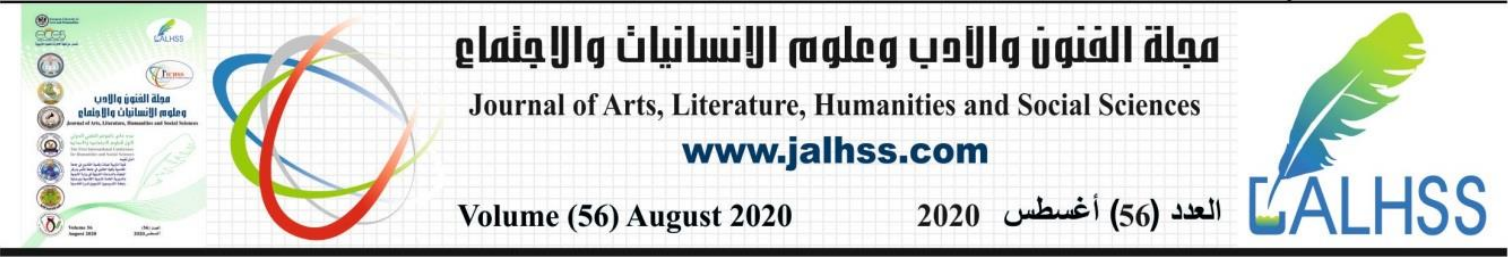

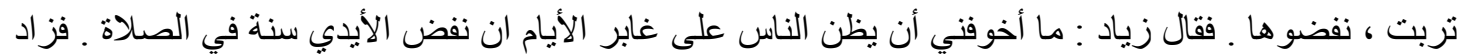

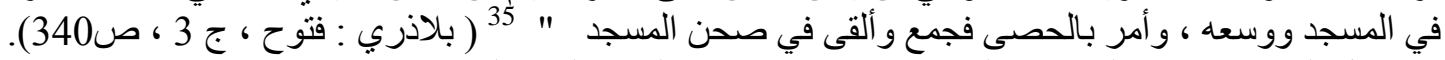

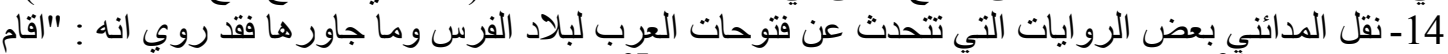

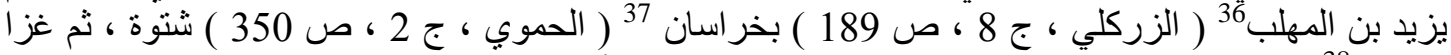

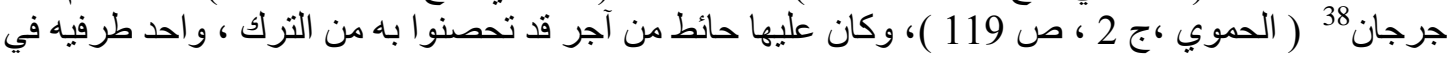

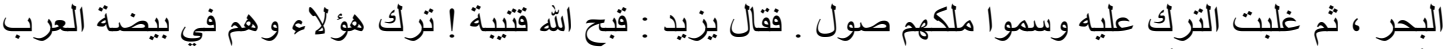

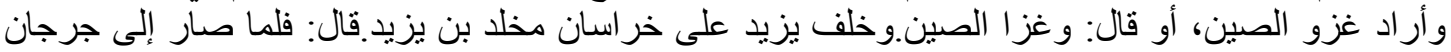

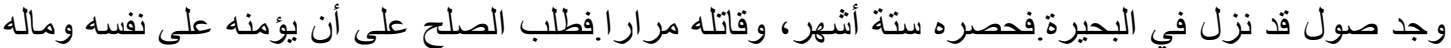

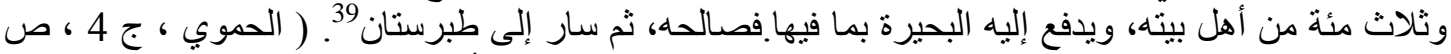

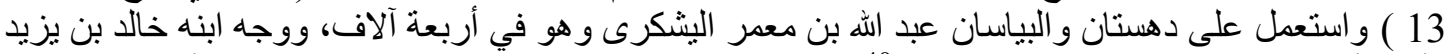

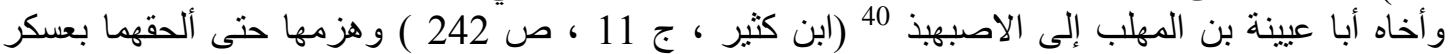

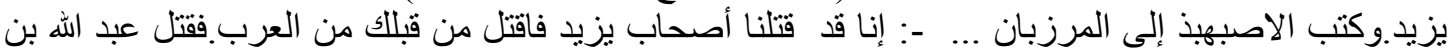

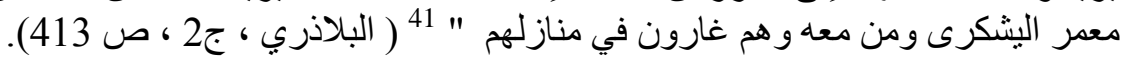

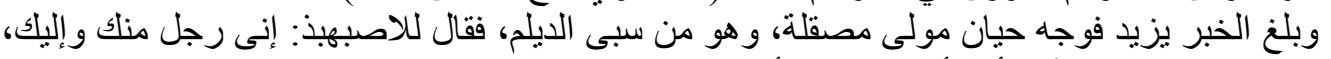

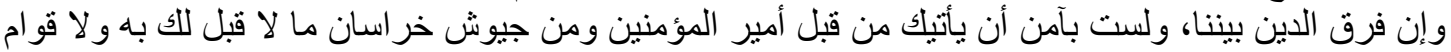

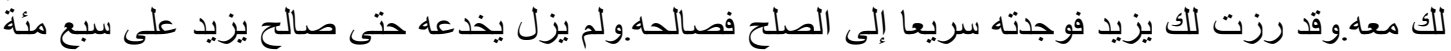

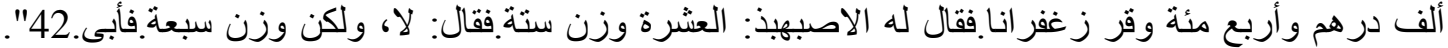

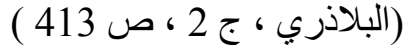

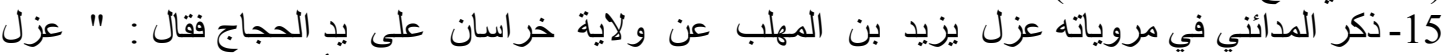

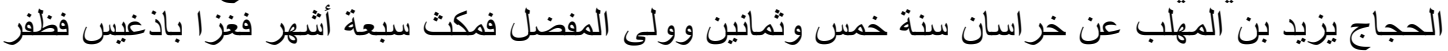

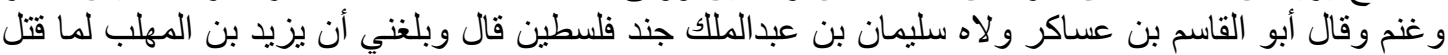

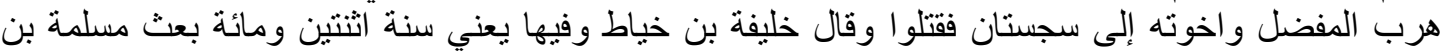

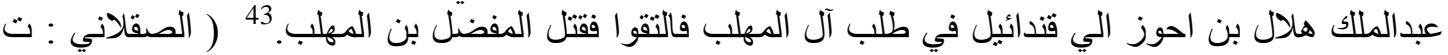

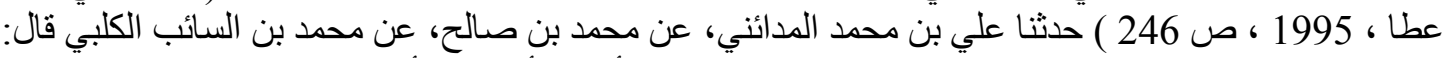

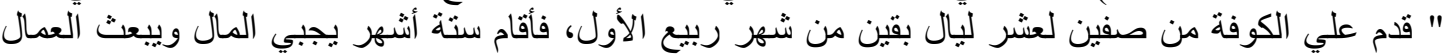

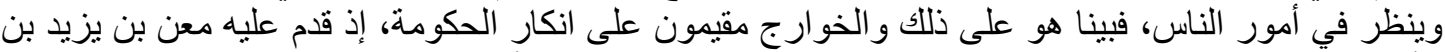

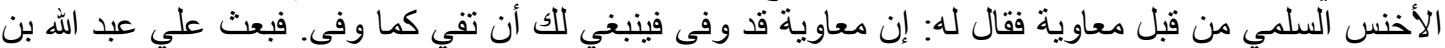

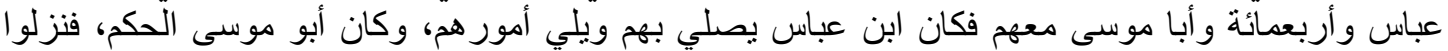

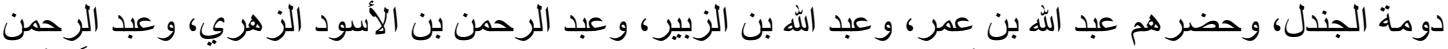

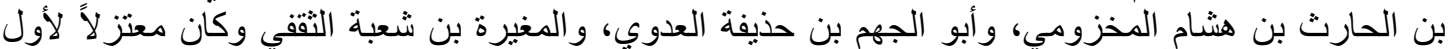

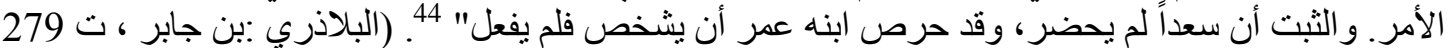

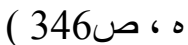

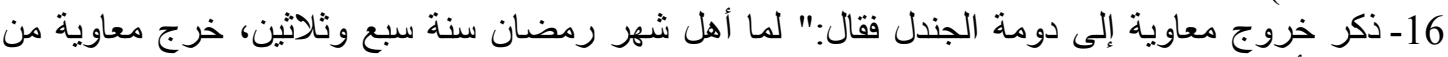

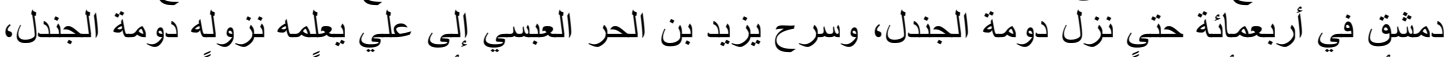

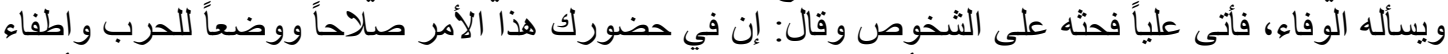

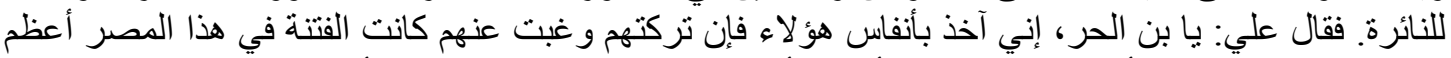

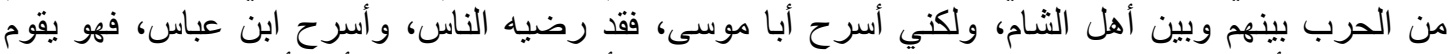

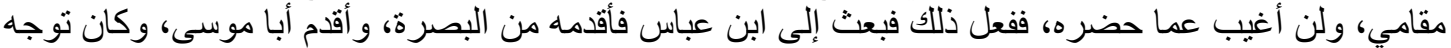

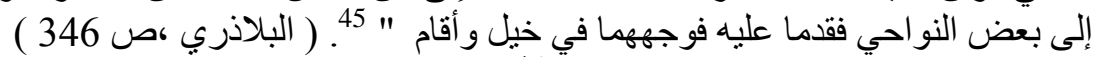

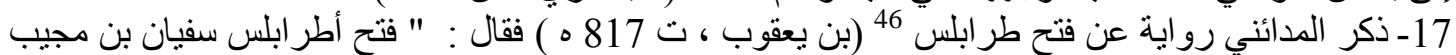

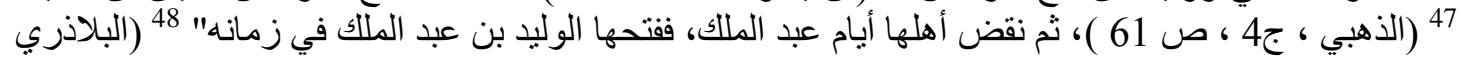

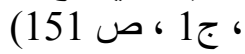




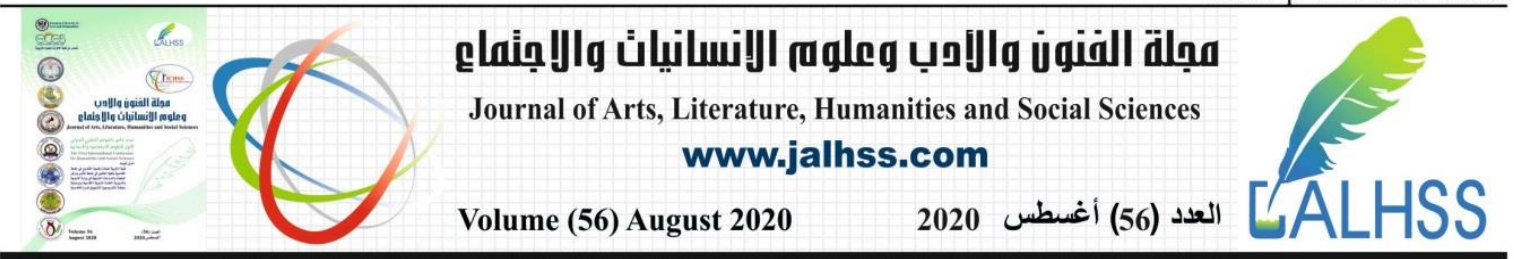

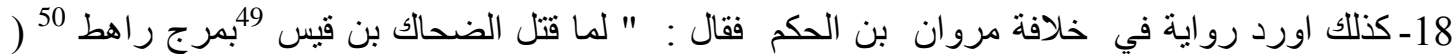

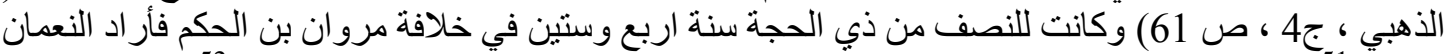

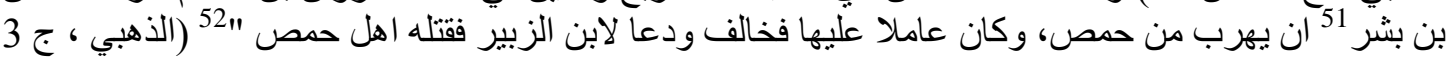

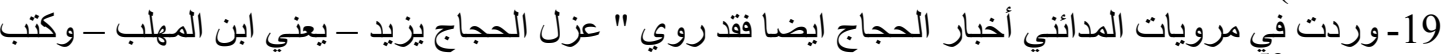

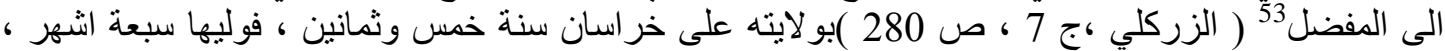

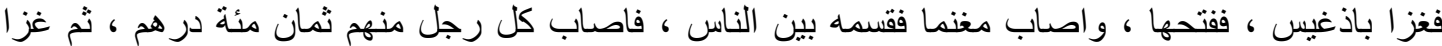

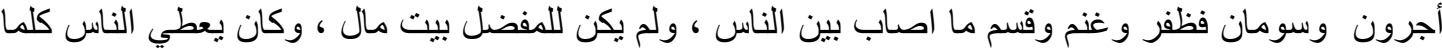

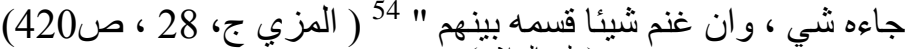

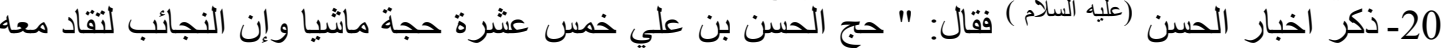

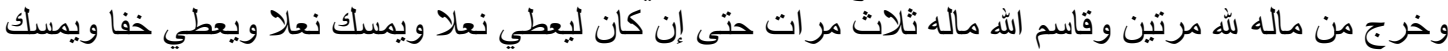

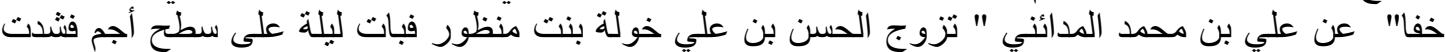

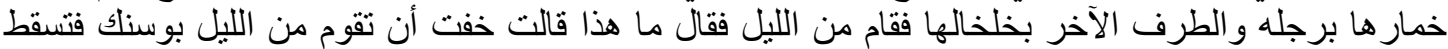

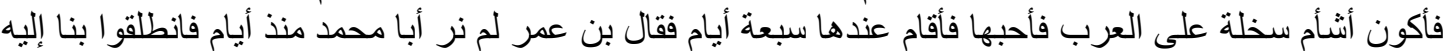

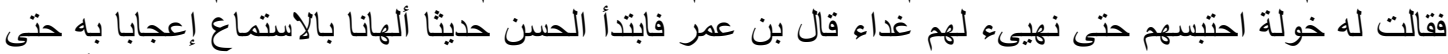
جاءنا الطعام قال المدائني وقال قوم التي شدت خمار ها برجله هند بنت سهيل بن عمرو وكان الحسن أحسن أحصن

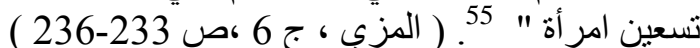

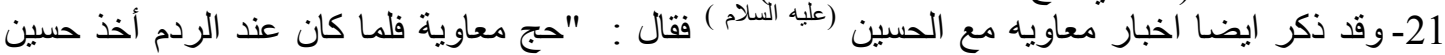

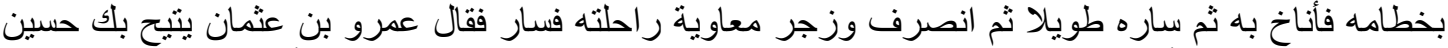

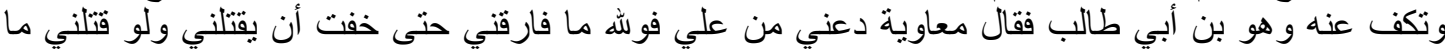

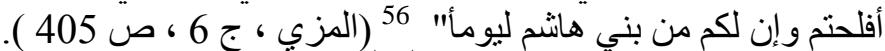

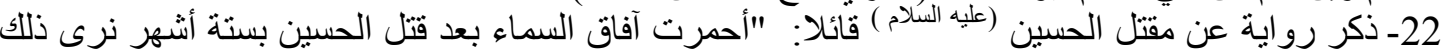

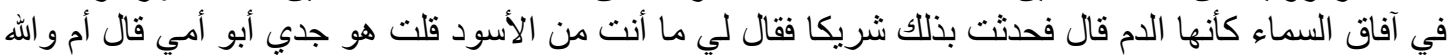

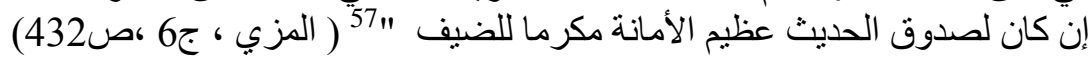

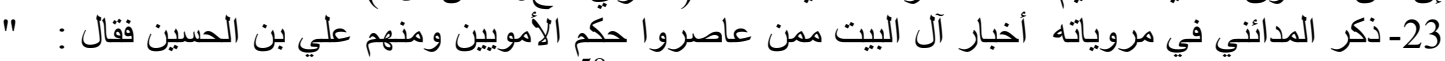

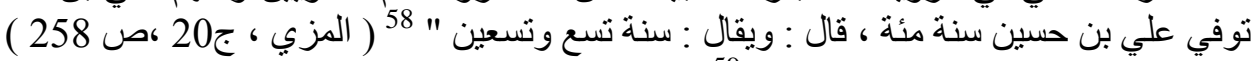

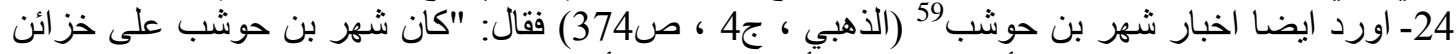

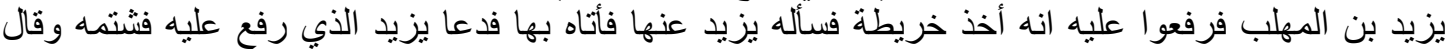

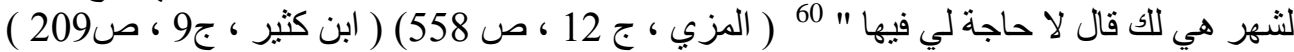

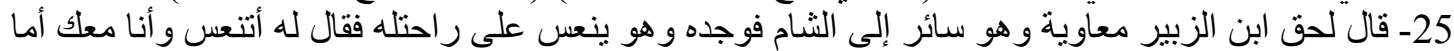

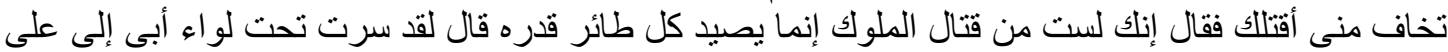

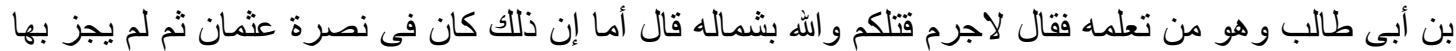

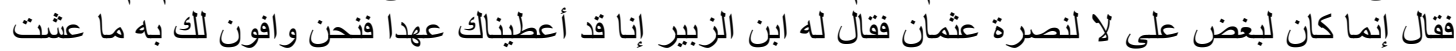

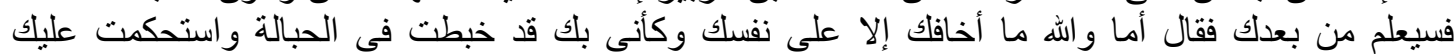

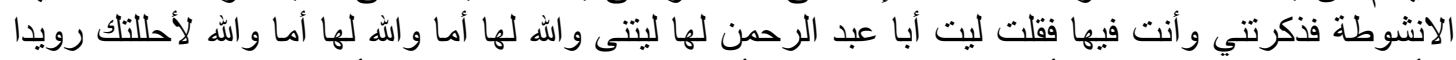

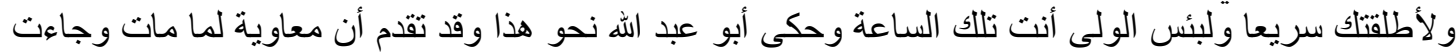

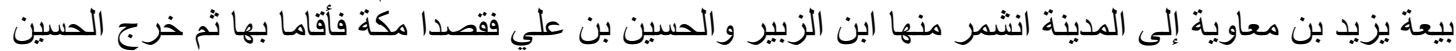

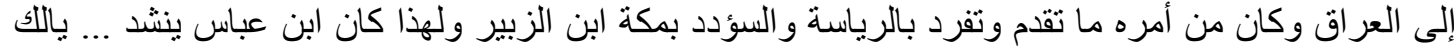

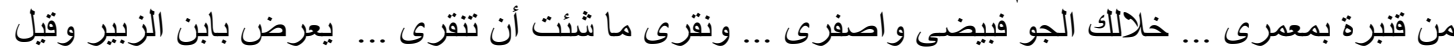

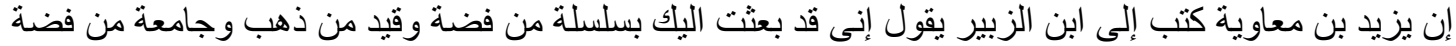

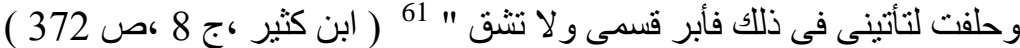

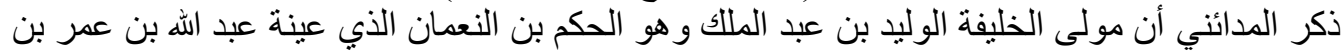

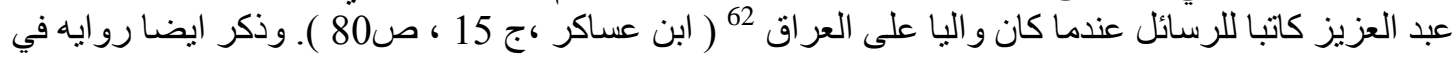




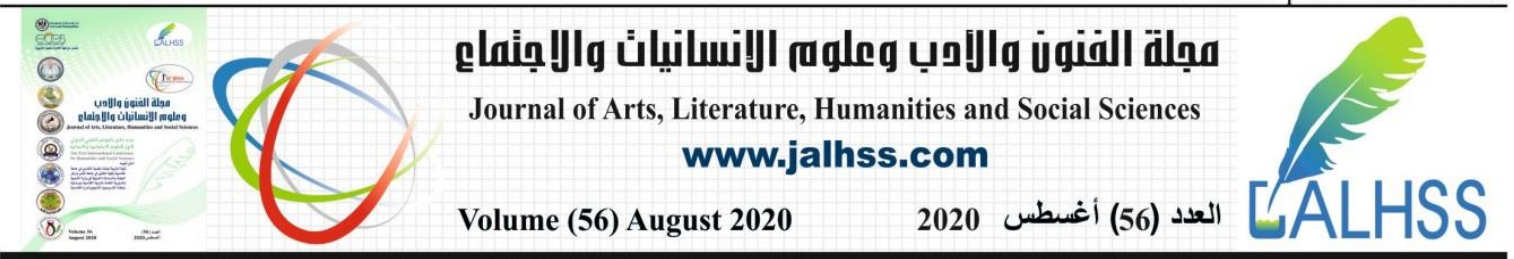

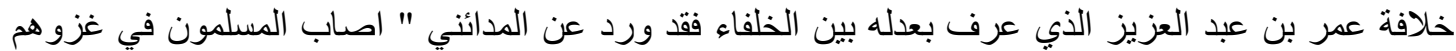

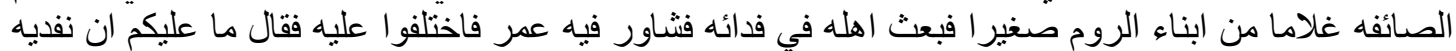

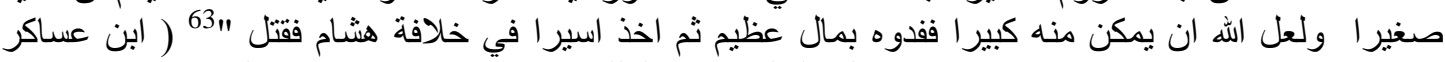

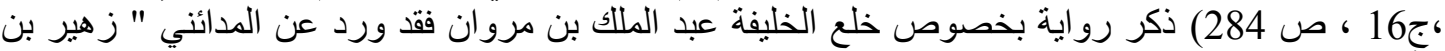

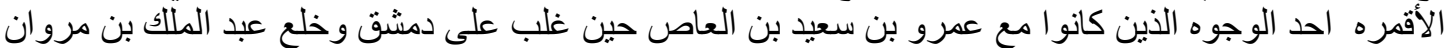

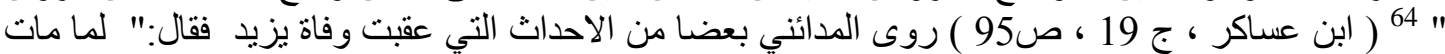

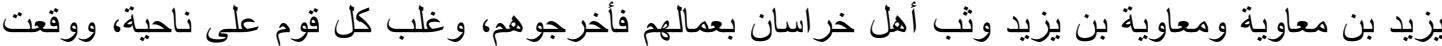

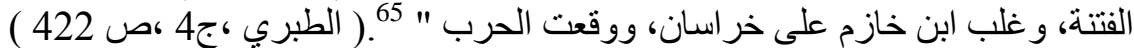

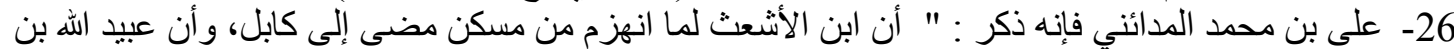

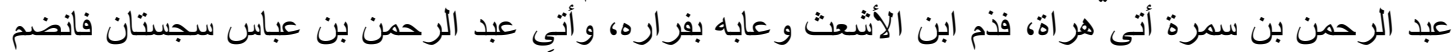

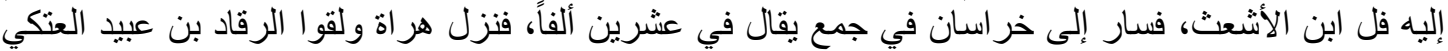

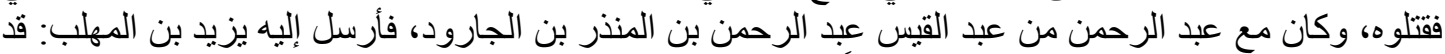

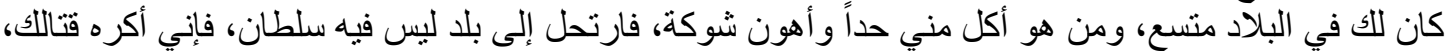

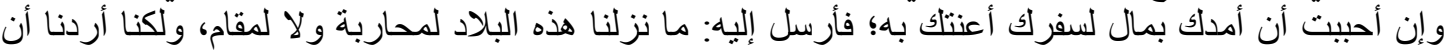

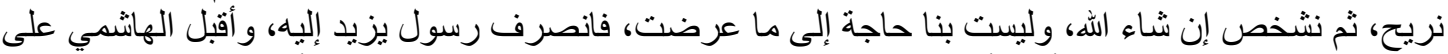

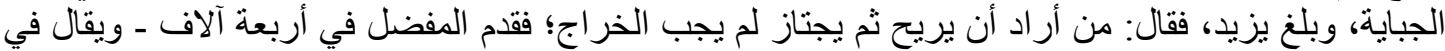

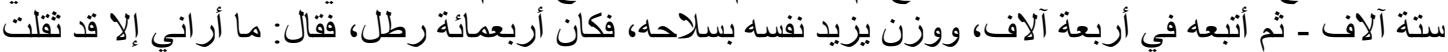

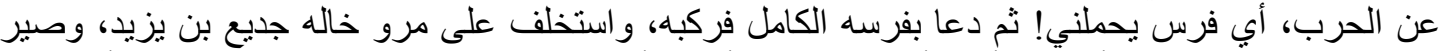

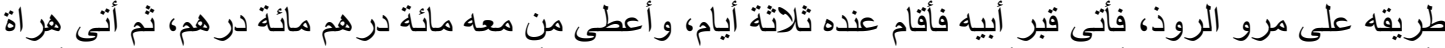

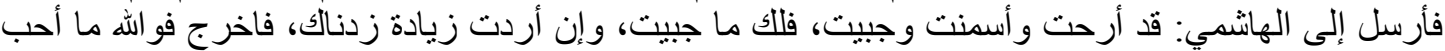

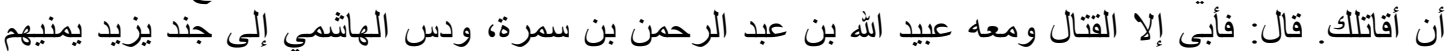

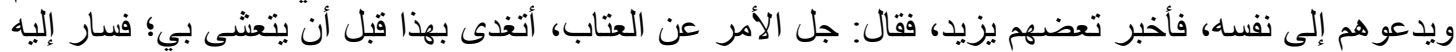

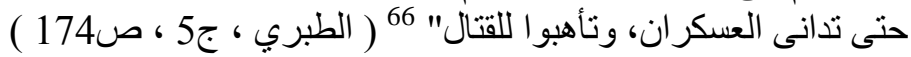

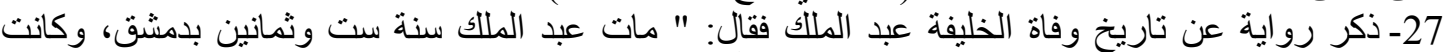

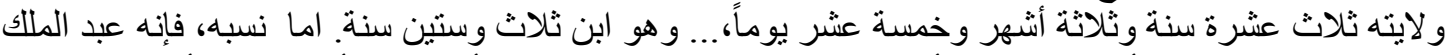

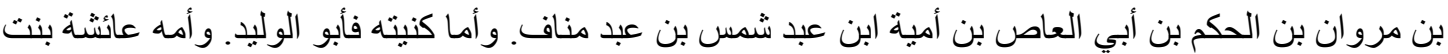

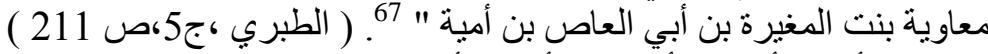

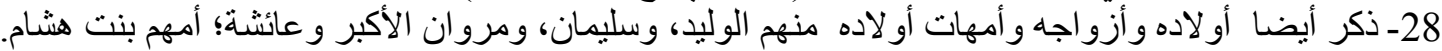

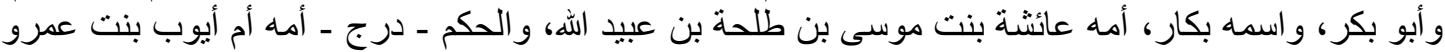

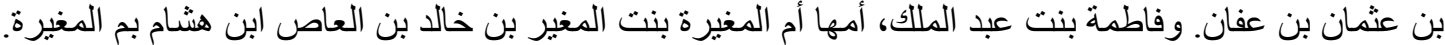

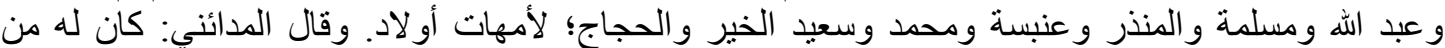
النساء ـ سوى من ذكرنا ـ شقر اء بنت سلمة ابن حلبس الطائي، وابنة لعلي بن أبي طالب عليه عليه السلام، وأم أبيها

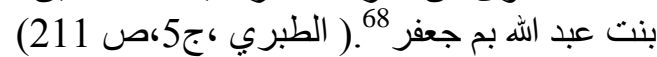

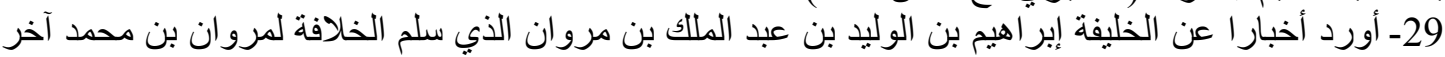

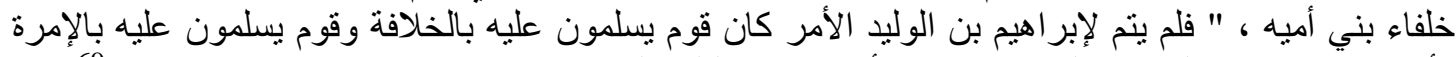

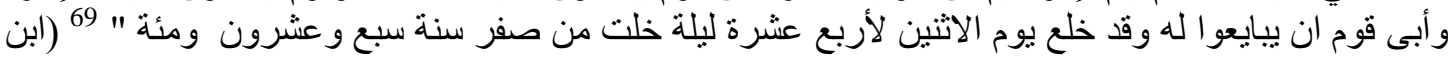

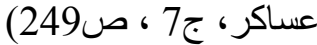

الخاتمة

الحمد لله رب العالمين والصلاة والسلام على محمد خير المرسلين واله الطييين الطاهرين ، وصحبه

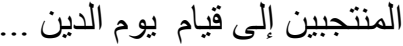
بعد الانتهاء من اعداد البحث توصل البن الباحث الى عدة نتائج كان اهمها : 


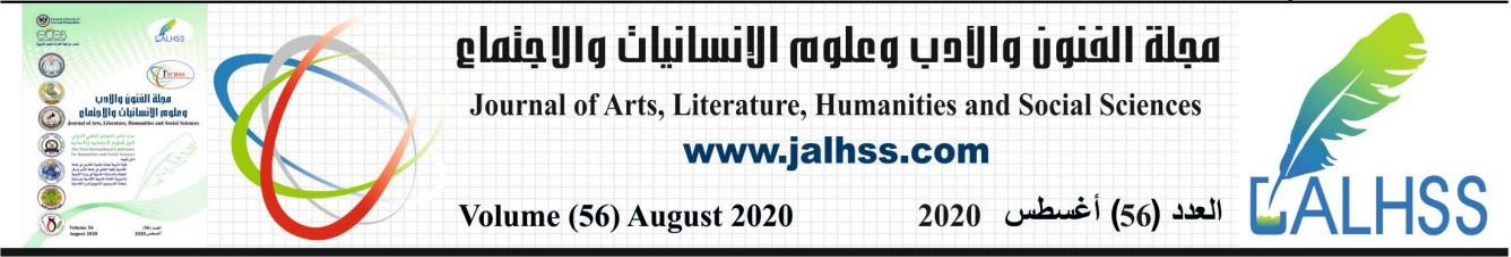

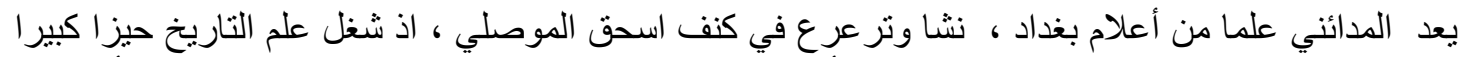

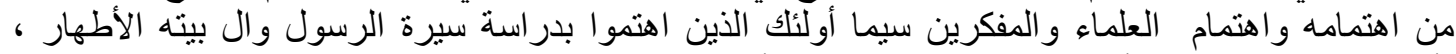

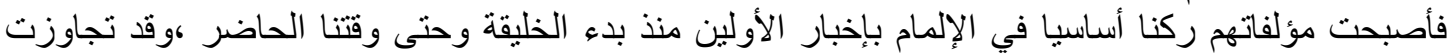

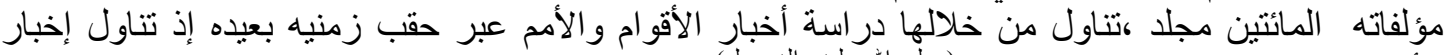

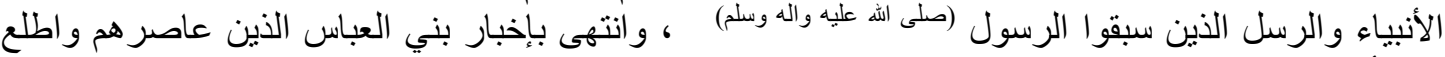

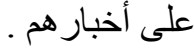

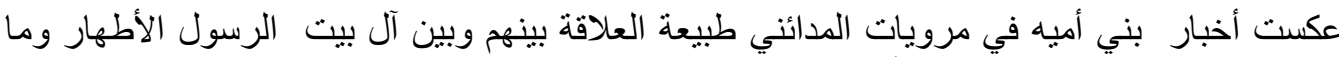

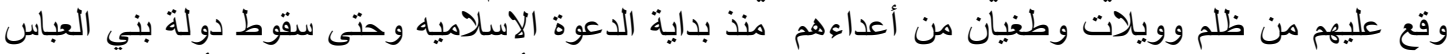

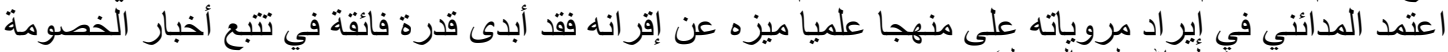

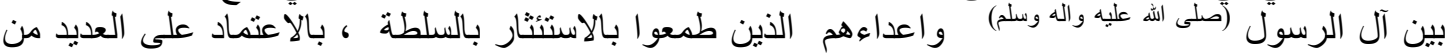

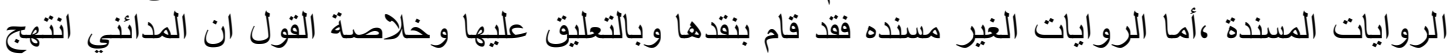

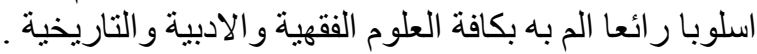
فضلا عن انه أجاد العلم و المعرفة كإجادته للشعر وإتقانه للفنون العلمية الدينية ومبادئها و الوقوف على أسر ارها

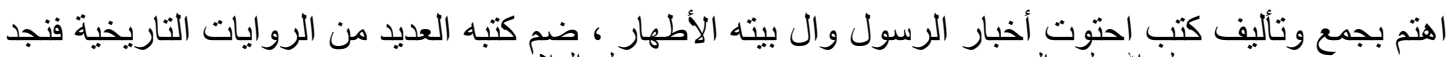

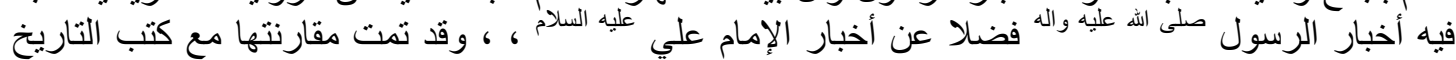
و الفقه.

\section{الهو امش}

1 ـ العلامه الحلي ، ابو منصور الحسن بن يوسف (ت: 726 هـ) ، خلاصة الاقو ال في معرفة الرجال ،تح: جو اد القيومي

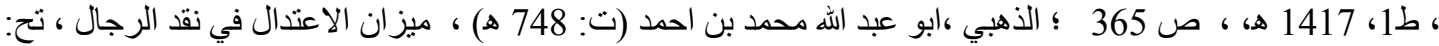

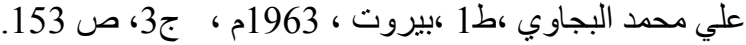

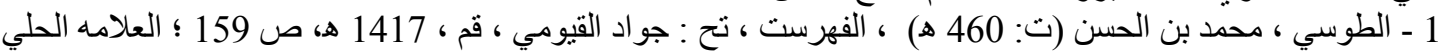

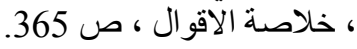

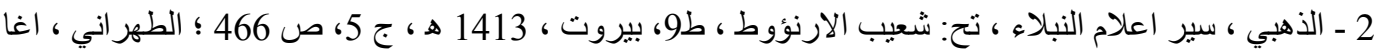

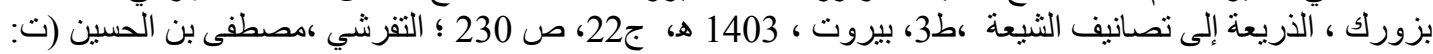

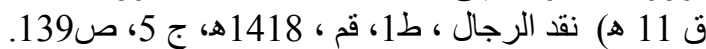

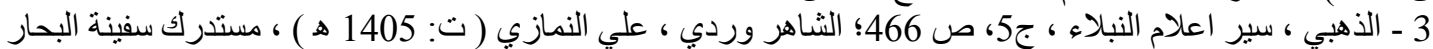

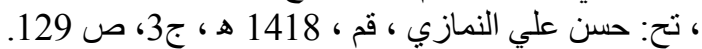

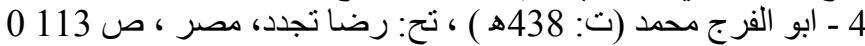

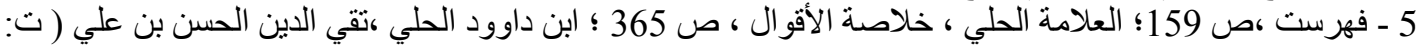

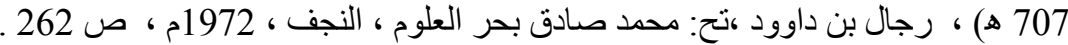

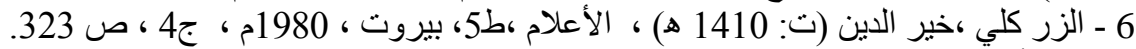

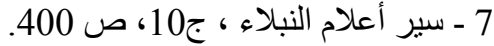

8 - الخطيب البغدادي ، ابي بكر احمد بن علي (ت): 463 هـ) ، تاريخ بغداد ، تح: مصطفى عبد القادر ، 1997م ، خج12

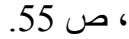
9 - شهاب الدين ابي الفضل (ت: 852 هـ ) ، لسان الميزان ،ط2، بيروت ، 1971 م ، ج4 ، ص 253. 10 - 10 - 10

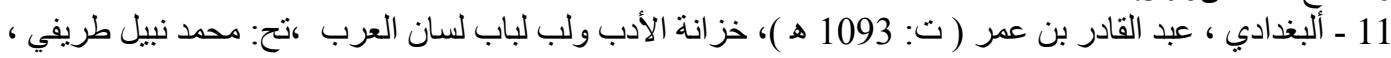

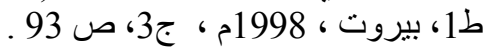

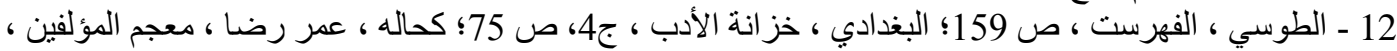

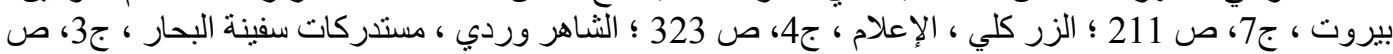




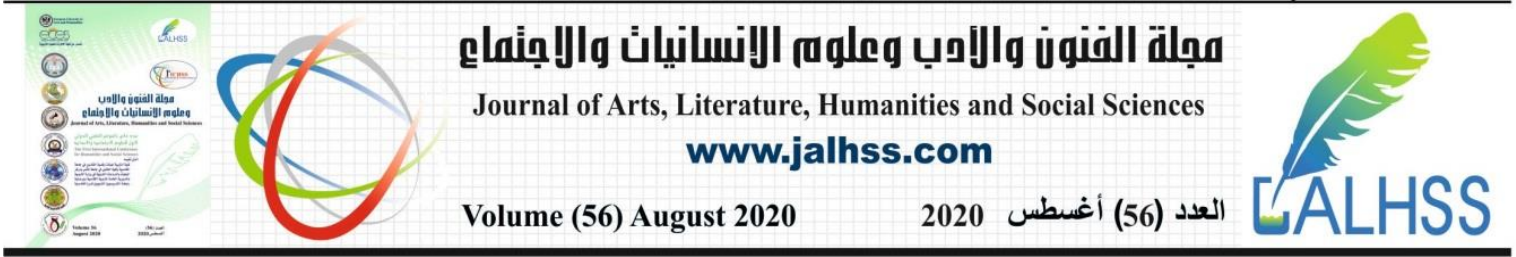

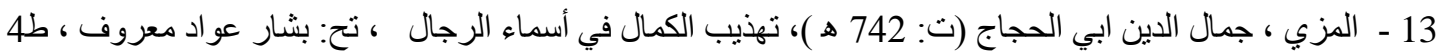

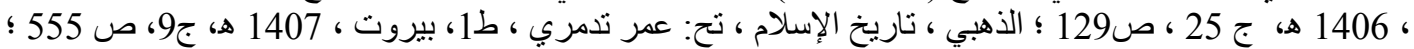

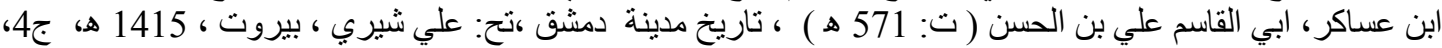

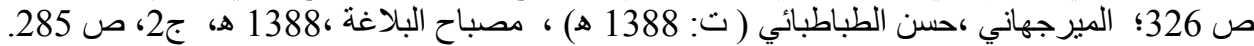

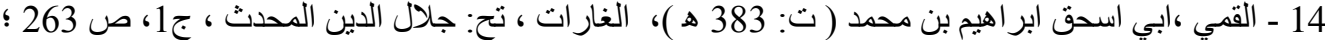

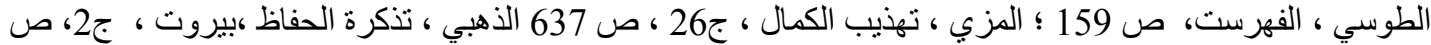

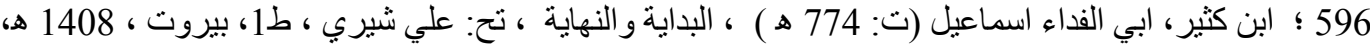

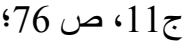

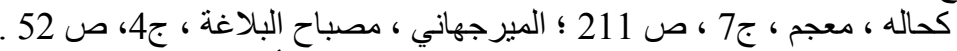

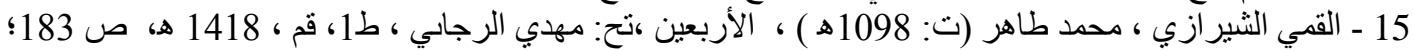

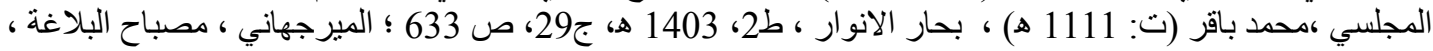

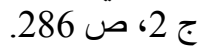

16 - مرو : بلده من بلاد خر اسان ينظر : ألطريحي ، فخر الدين (ت: 1085 هـ )، مجمع البحرين ، تح: احمد الحسيني ،

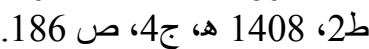
17 -دهاقين : جمع دهقان وتعني التاجر وهي كلمة فارسية معربة ينظر : ابن منظور ، جمال الدين محمد (ت: 711 هـ ) ،

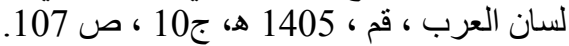
18 - ابر شهر : اسم لمدينة نيسابور بخر استان فتحها عنوة عبد الله بن عامر ينظر : الحموي ، شهاب الدين ابي عبد الله

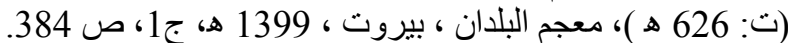

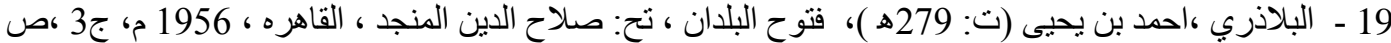

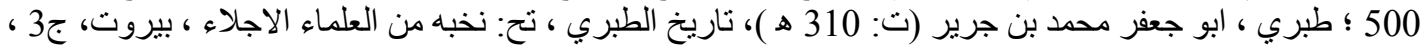

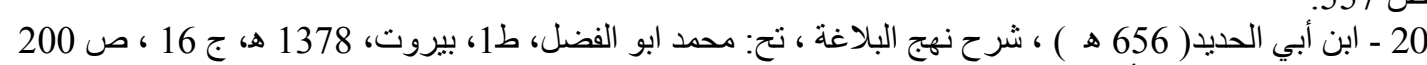

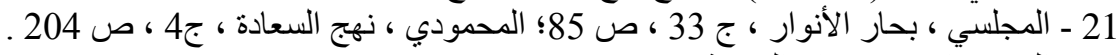

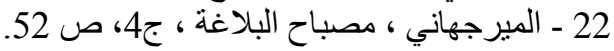

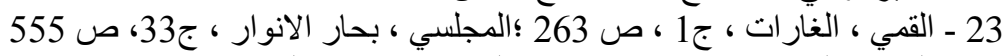

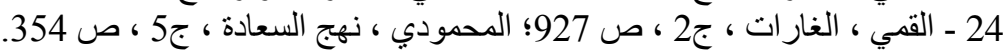

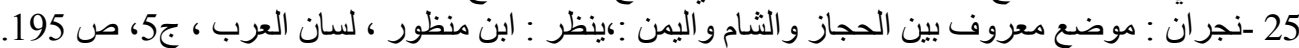

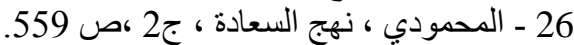

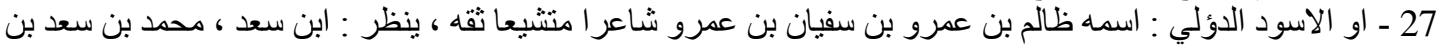

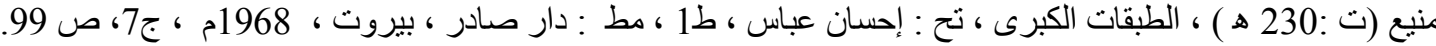

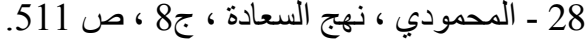

29 - الري : مدينة مشهورة من امهات البلاد ، و وهي محط الحجاج بينها وبين نيسابور 160 فرسخ ؛ ينظر : الحموي ،

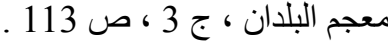

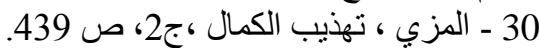
31 - عبد الله بن الزبير بن العوام القرشي ، الاسدي ، بويع له بالخلافة سنة 64 هـ ، توفي سنة 73 هـ؛ بنظر : الدزي ،

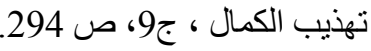

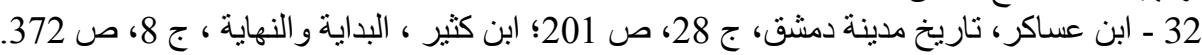

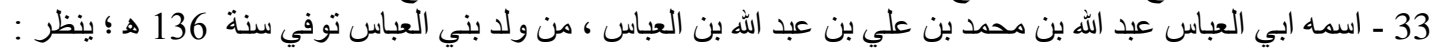

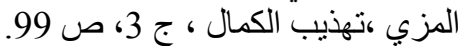
34 - ابن اعثم الكوفي ، احمد (ت) 314 314هـ ) ، الفتوح ، تح : علي شيري ، ط1، بيروت ، 1411 هـ، ج8، ص 341.

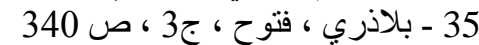

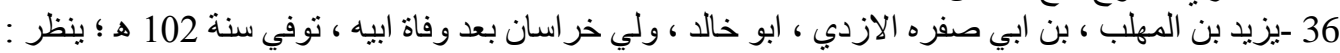

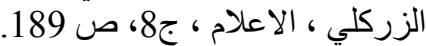

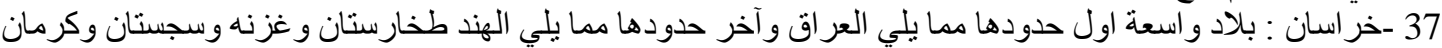

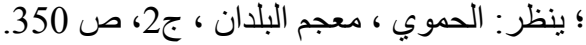




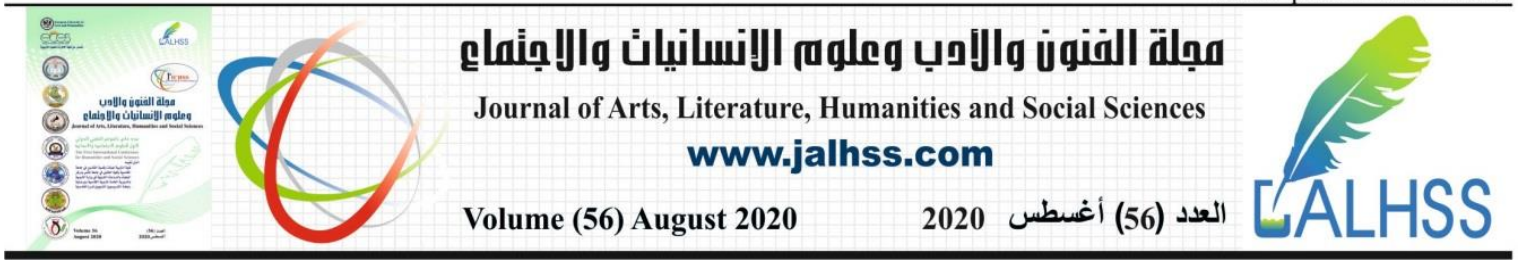

38 - جرجان : بضم اوله تقع في الاقليم الر ابع وبعضهم يذكر انها في الاقليم الخامس ، مدينة مشهورة بين طبرستان

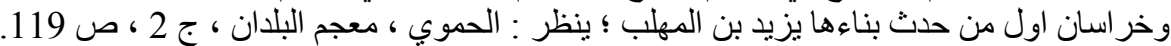

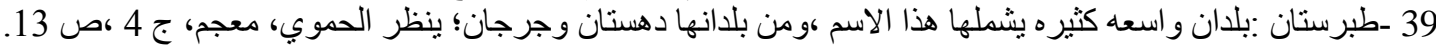

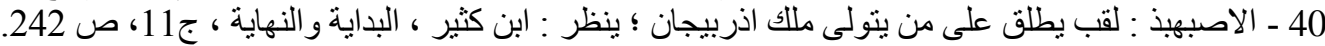

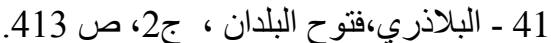

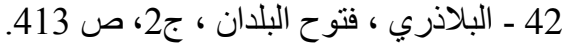
43 ـ ابن حجر العسقلاني ، تقريب التهذيب ، تح : 1992 ، مصطفى عبد القادر عطا ، ط2، مط : دار الكتب العلمية ، بيروت

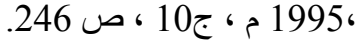
44 ـ البلاذري ، احمد بن يحيى بن جابر (ت: 279هـ) ، انساب الأشراف ، تح: محمد باقر المحمودي ، مط : الأعلمي ،

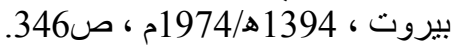

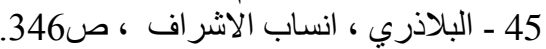

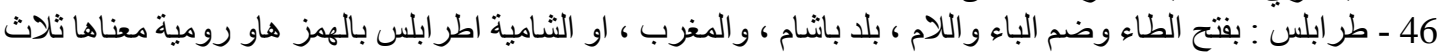
مدن ؛ ينظر : الفيروز آبادي ، مجد الدين محمد بن يعقوب (ت:

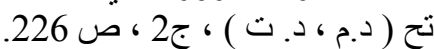
47 - سفيان بن مجيب من صحابة رسول الله (ص) ولي بعلبك بزمن معاوية ؛ ينظر : الذهبي ، تاريخ الاسلام ، ج4 ، ص

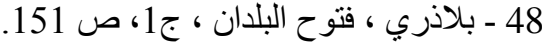

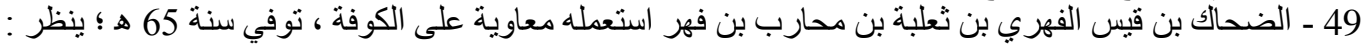

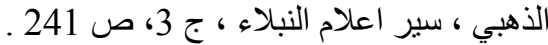

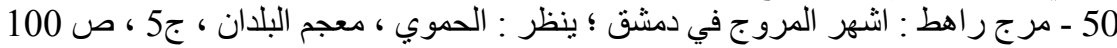

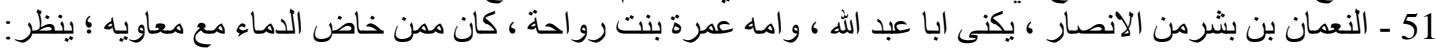

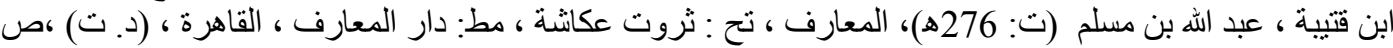

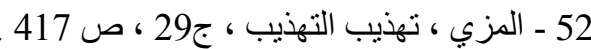

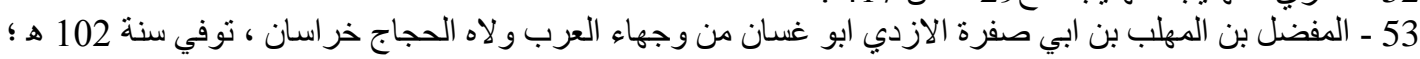

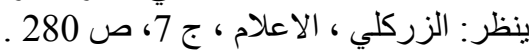

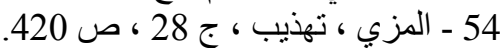

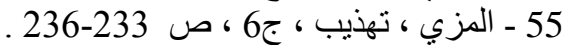

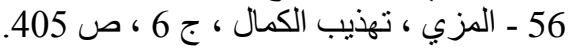

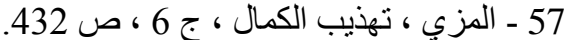

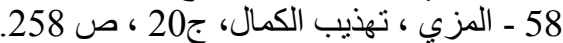
59 - شهر بن حوشب : اسمه ابو ابو سعيد الاشعري الثامي مولى الصحابيه اسماء بنت يزيد الانصارية ؛ ينظر : الذهبي ،

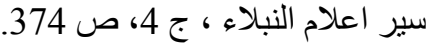

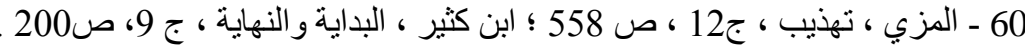

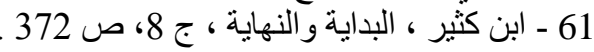

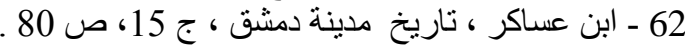

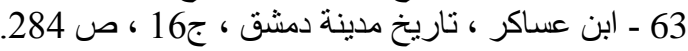

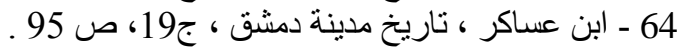

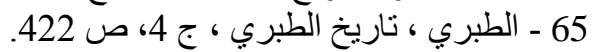

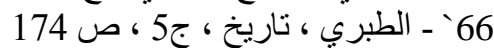

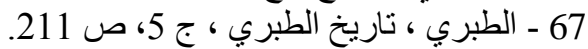

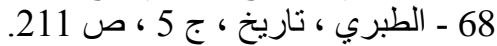

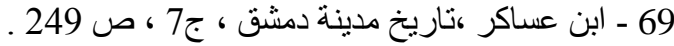




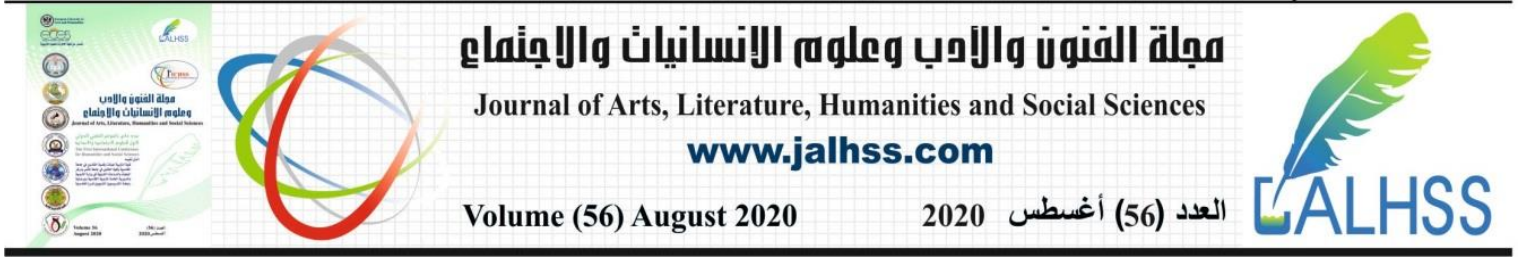

1.ابو الفضل ، محمد ، 1378ه ، شرح نهج البلاغة ، ط1 ، ب بيروت

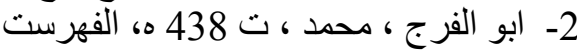

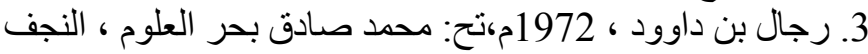

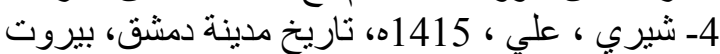

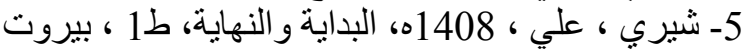

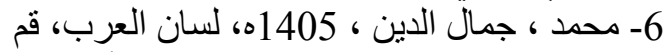

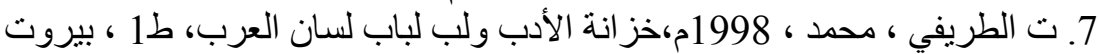

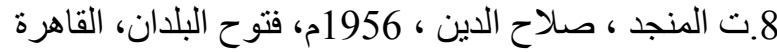

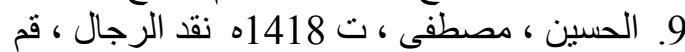

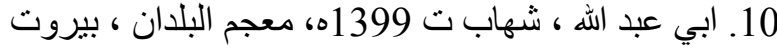

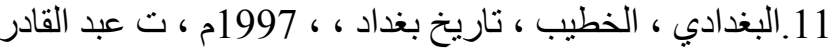

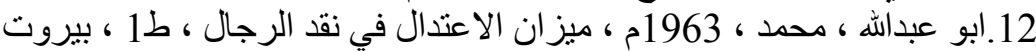

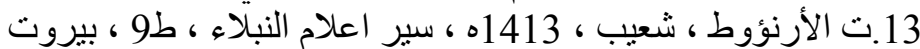

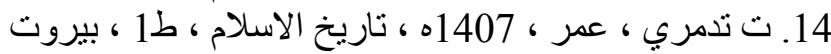

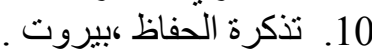

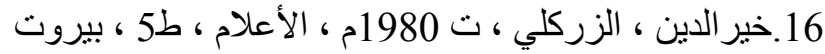

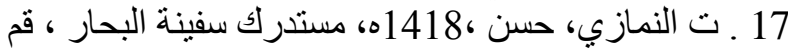

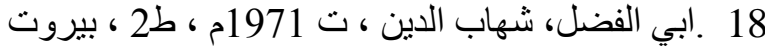

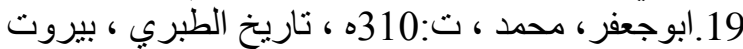

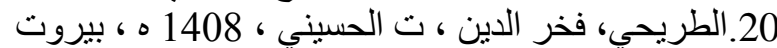

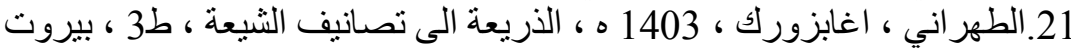

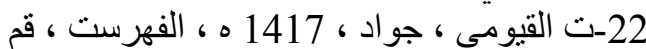

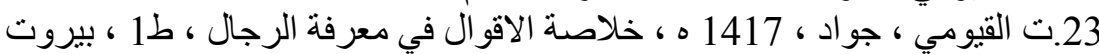

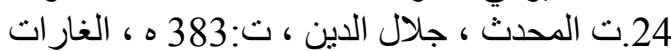

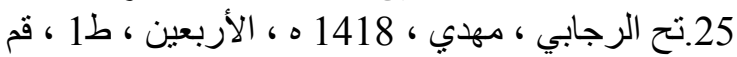

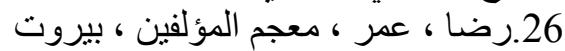

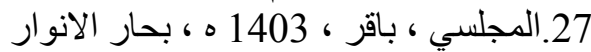

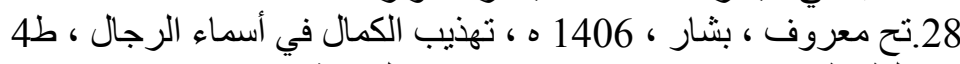

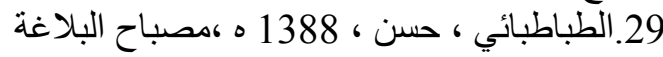




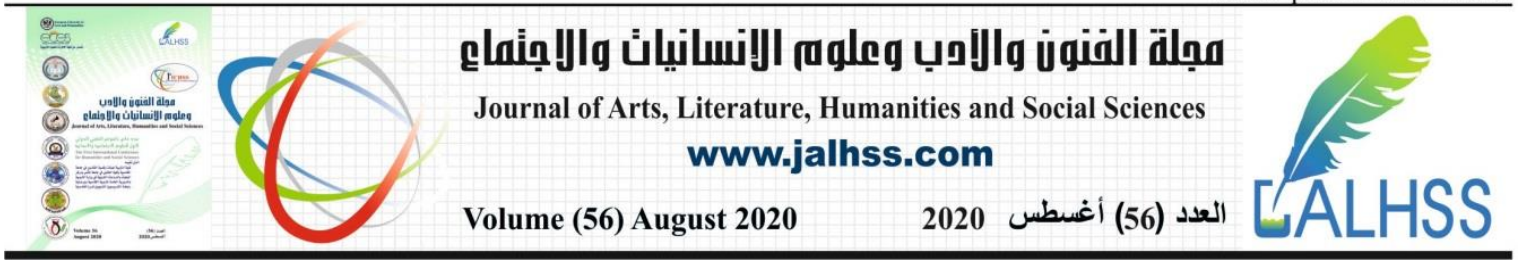

\section{References}

1. Abu Al-Fadl, Muhammad, 1378 AH, Explaining the Approach to Rhetoric, 1st Edition, Beirut

2- Abu Al-Faraj, Mohammed, 438 H, Al-Fihrist

3. Rijal bin Dawood, 1972 AD, Tah: Muhammad Sadiq Bahr Al-Ulum, Najaf

4- Sherry, Ali, 1415 AH, History of the City of Damascus, Beirut

5- Sherry, Ali, $1408 \mathrm{AH}$, The beginning and the end, 1st edition, Beirut

6- Muhammad, Jamal Al-Din, 1405 AH, Tongan of the Arabs, Qom

7. Al-Turifi T, Muhammad, 1998 AD, Treasury of Literature and the Pulp of the Tongue of the Arabs, 1st edition, Beirut

8. Al-Munajjid, Salah Al-Din, 1956 AD, Fattouh Al-Balad, Cairo

9. Al-Hussein, Mustafa, T 1418 AH, The Criticism of Men, Qom

10. Abi Abdullah, Shihab T 1399 AH, Glossary of countries, Beirut

11. Al-Baghdadi, Al-Khatib, History of Baghdad, 1997 AD, Abdul Qadir

12. Abu Abdullah, Muhammad, 1963 AD, The Balance of Moderation in Men's Criticism, 1st Edition, Beirut

13. Al-Arnaout, Shuaib, 1413 AH, Biography of the Nobles Flags, 9th Edition, Beirut

14. Tadmouri, Omar, 1407 AH, History of Islam, 1st edition, Beirut

10. Conservation ticket, Beirut.

16. Khair al-Din, Al-Zarkali, 1980 AD, Al-Alam, 5th edition, Beirut

17. T. Al-Namazi, Hasan, 1418 AH, revealing the ship of the seas, Qom

18. Abi Al-Fadl, Shehab Al-Din, 1971 AD, 2nd edition, Beirut

19 Abu Ja far, Muhammad, Tel: $310 \mathrm{H}$, History of al-Tabari, Beirut

20. Al-Turaihi, Fakhr Al-Din, Al-Husseini T, 1408 AH, Beirut

21. Al-Tahrani, Aghabzurk, 1403 AH, Al-Hadhirah to Shia Classifications, 3rd Edition, Beirut.

22-T Al-Qayoumi, Jawad, 1417 AH, Al-Fihrest, Qom

23. Al-Qayoumi, Jawad, 1417 AH, Summary of Sayings on Knowledge of Men, 1st

Edition, Beirut

24. The updated, Jalaluddin, Tel: $383 \mathrm{AH}$, raids

25. Tahat Al-Rajabi, Mahdi, 1418 AH, Al-Arbaeen, 1st Edition, Qom

26. Reda, Omar, Authors' Dictionary, Beirut

27. Al-Majlisi, Baqer, 1403 AH, Bahar Al-Anwar

28. Tahr Ma ruf, Bashar, 1406 AH, Refining the Perfection in the Names of Men, 4th edition

29. Tabatabai, Hasan, 1388 AH, Mesbah al-Balagha. 